\title{
Exploration of the Mitsunobu Reaction with Tosyl- and Boc-Hydrazones as Nucleophillic Agents
}

John M. Keith ${ }^{*}$ and Leslie Gomez

Supplementary Information 
Table of Contents

\begin{tabular}{|c|c|}
\hline Page \# & $\begin{array}{c}\text { Contents } \\
\end{array}$ \\
\hline S3 & Compound $3,{ }^{1} \mathrm{H}$ NMR \\
\hline S4 & Compound $3,{ }^{13} \mathrm{C}$ NMR \\
\hline S5 & Compound $4,{ }^{1} \mathrm{H}$ NMR \\
\hline S6 & Compound $4,{ }^{13} \mathrm{C}$ NMR \\
\hline S7 & Compound $5,{ }^{1} \mathrm{H}$ NMR \\
\hline S8 & Compound 5, ${ }^{13} \mathrm{C}$ NMR \\
\hline S9 & Compound $6,{ }^{1} \mathrm{H}$ NMR \\
\hline S10 & Compound 6, ${ }^{13} \mathrm{C}$ NMR \\
\hline S11 & Compound $7,{ }^{1} \mathrm{H}$ NMR \\
\hline S12 & Compound $7,{ }^{13} \mathrm{C}$ NMR \\
\hline S13 & Compound $8,{ }^{1} \mathrm{H}$ NMR \\
\hline S14 & Compound 8, ${ }^{13} \mathrm{C}$ NMR \\
\hline S15 & Compound 9, ${ }^{1} \mathrm{H}$ NMR \\
\hline S16 & Compound 9, ${ }^{13} \mathrm{C}$ NMR \\
\hline S17 & Compound $10,{ }^{1} \mathrm{H}$ NMR \\
\hline S18 & Compound 10, ${ }^{13} \mathrm{C}$ NMR \\
\hline S19 & Compound $11,{ }^{1} \mathrm{H}$ NMR \\
\hline $\mathbf{S 2 0}$ & Compound $11,{ }^{13} \mathrm{C}$ NMR \\
\hline $\mathbf{S 2 1}$ & Compound $12,{ }^{1} \mathrm{H}$ NMR \\
\hline $\mathbf{S 2 2}$ & Compound $12,{ }^{13} \mathrm{C}$ NMR \\
\hline $\mathbf{S 2 3}$ & Compound $13,{ }^{1} \mathrm{H}$ NMR \\
\hline S24 & Compound $13,{ }^{13} \mathrm{C}$ NMR \\
\hline $\mathbf{S 2 5}$ & Compound $14,{ }^{1} \mathrm{H}$ NMR \\
\hline S26 & Compound $14,{ }^{13} \mathrm{C}$ NMR \\
\hline S27 & Compound $15,{ }^{1} \mathrm{H}$ NMR \\
\hline S28 & Compound $15,{ }^{13} \mathrm{C}$ NMR \\
\hline $\mathbf{S 2 9}$ & Compound $16,{ }^{1} \mathrm{H}$ NMR \\
\hline S30 & Compound $16,{ }^{13} \mathrm{C}$ NMR \\
\hline S31 & Compound 17, ${ }^{1} \mathrm{H}$ NMR \\
\hline S32 & Compound $17,{ }^{13} \mathrm{C}$ NMR \\
\hline S33 & Compound $18,{ }^{1} \mathrm{H}$ NMR \\
\hline S34 & Compound $18,{ }^{13} \mathrm{C}$ NMR \\
\hline S35 & Compound $19,{ }^{1} \mathrm{H}$ NMR \\
\hline S36 & Compound 19, ${ }^{13} \mathrm{C}$ NMR \\
\hline S37 & Compound $20,{ }^{1} \mathrm{H}$ NMR \\
\hline S38 & Compound $20,{ }^{13} \mathrm{C}$ NMR \\
\hline
\end{tabular}




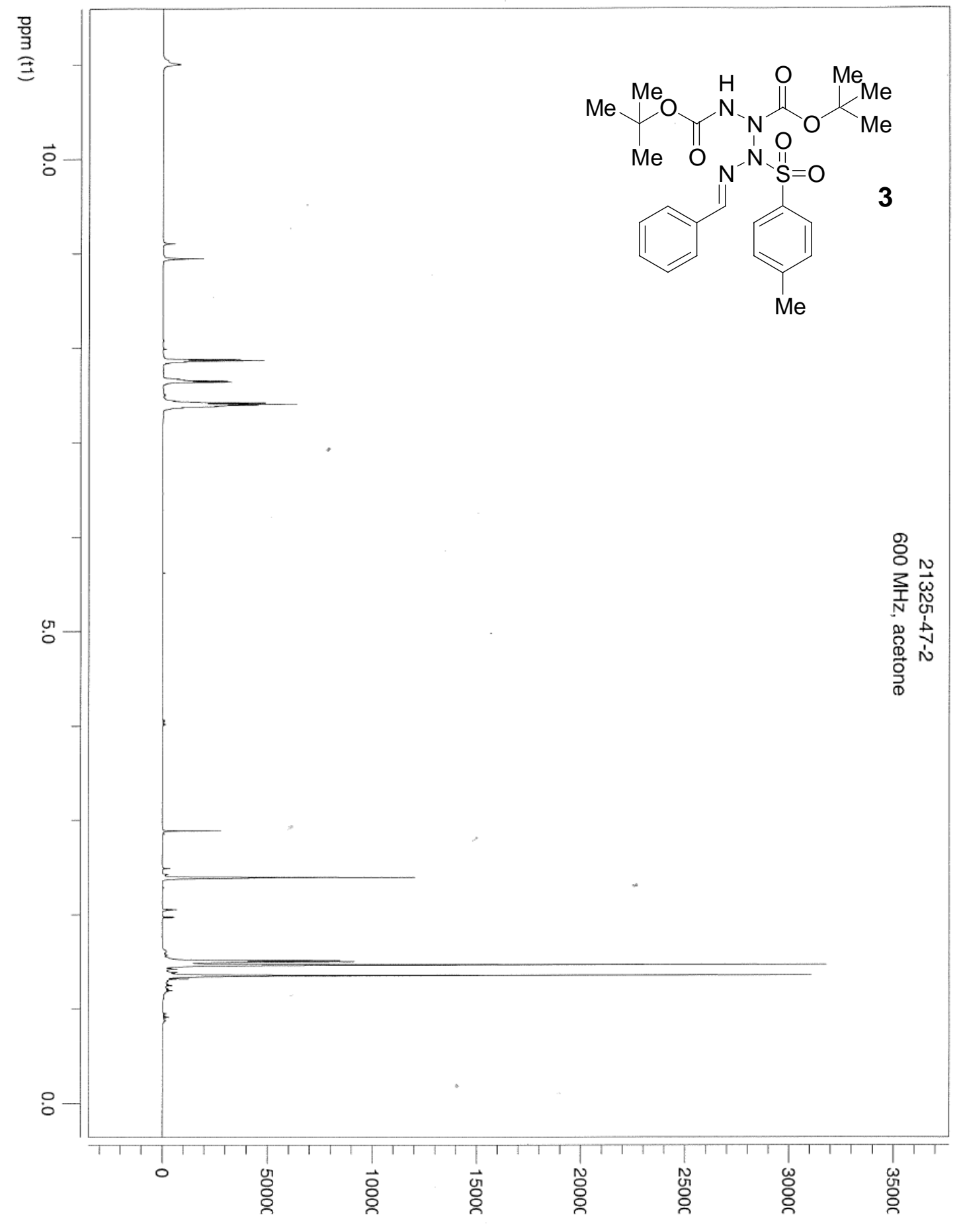




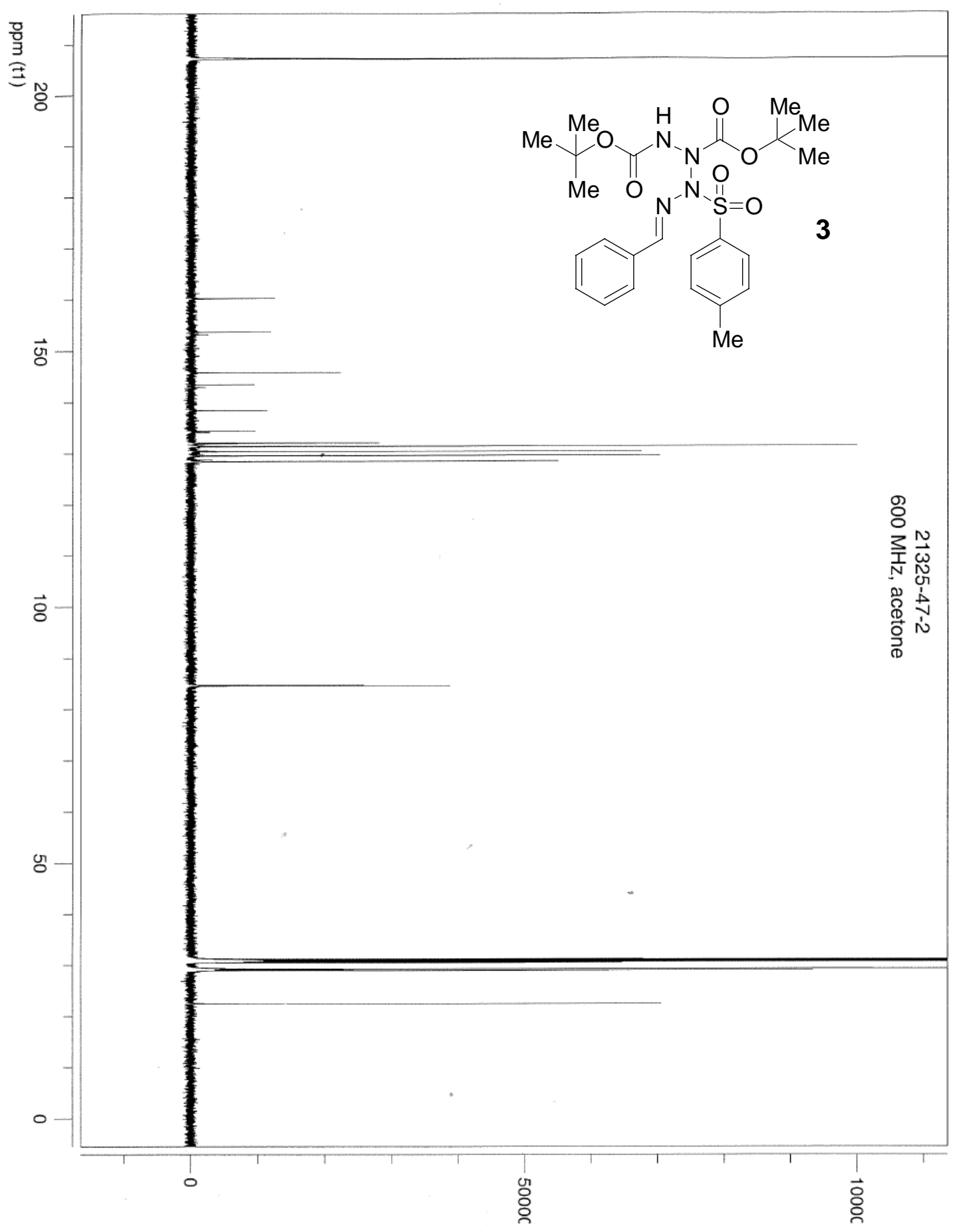




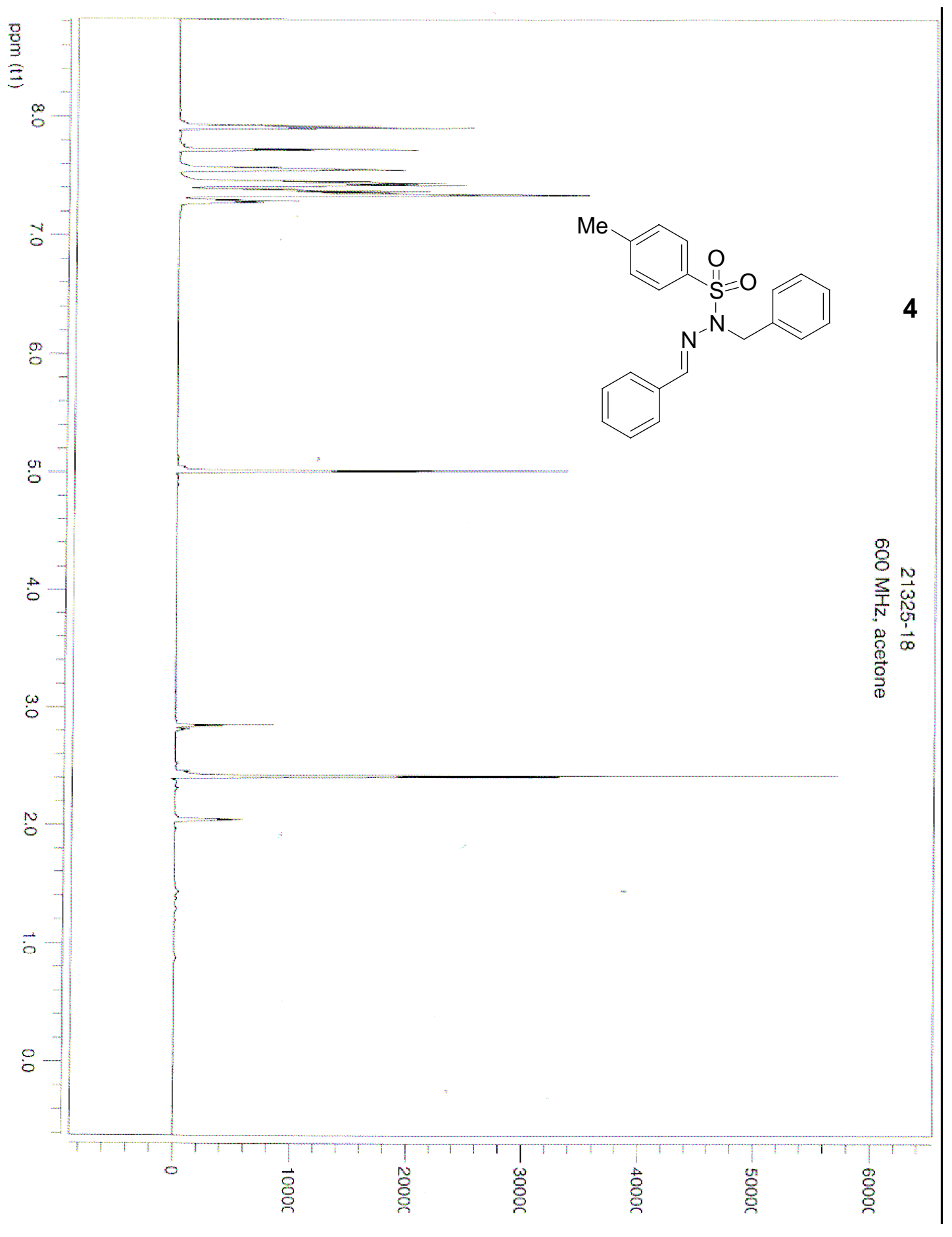




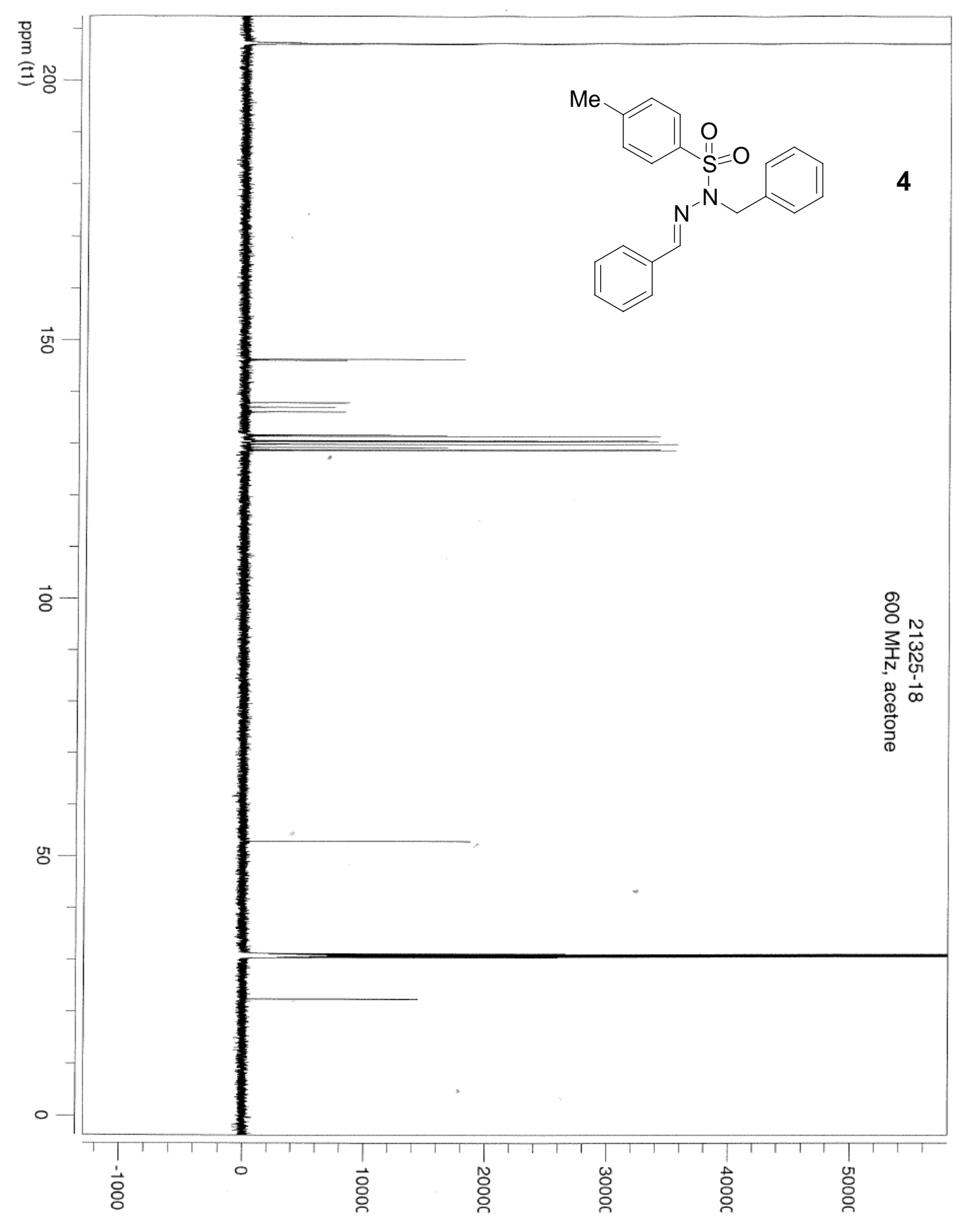




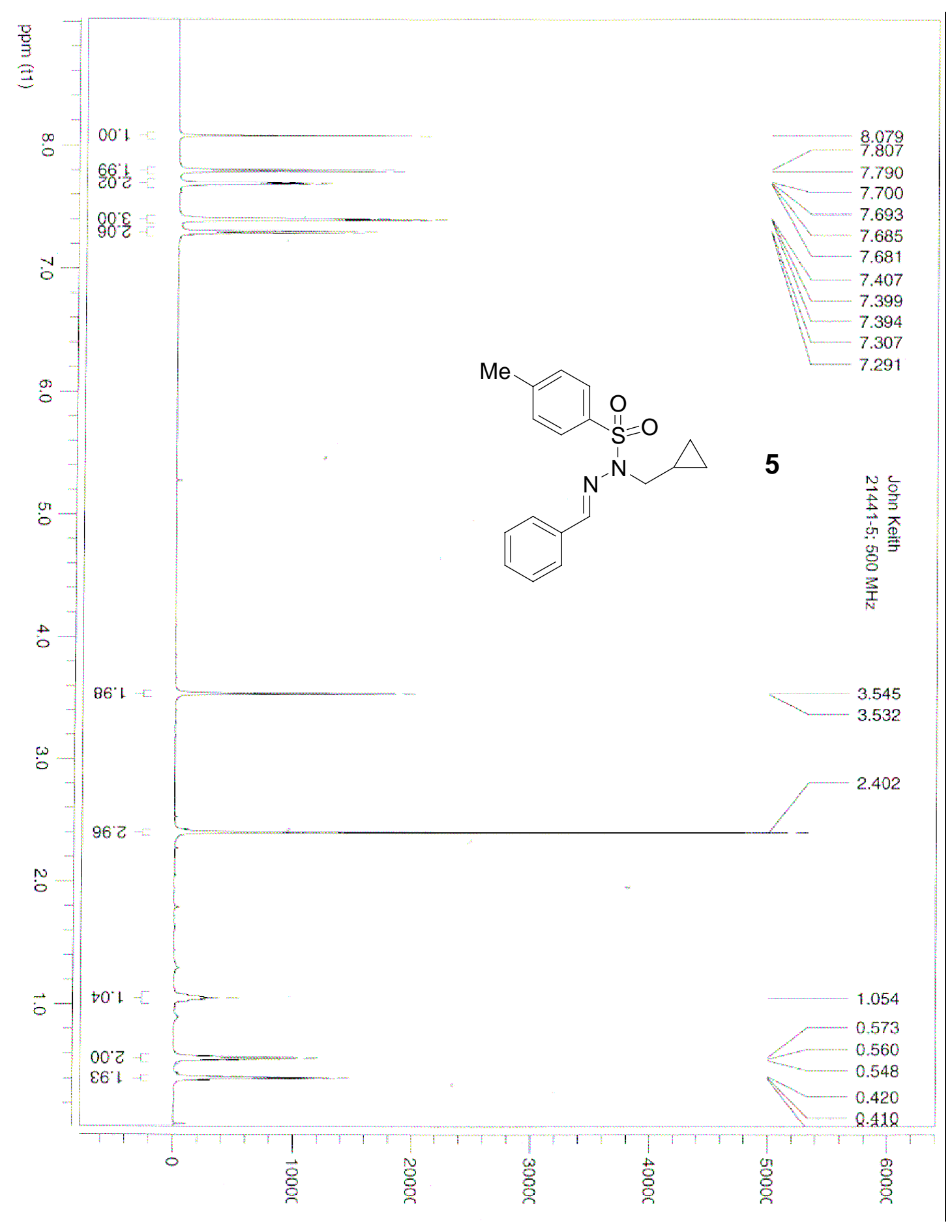




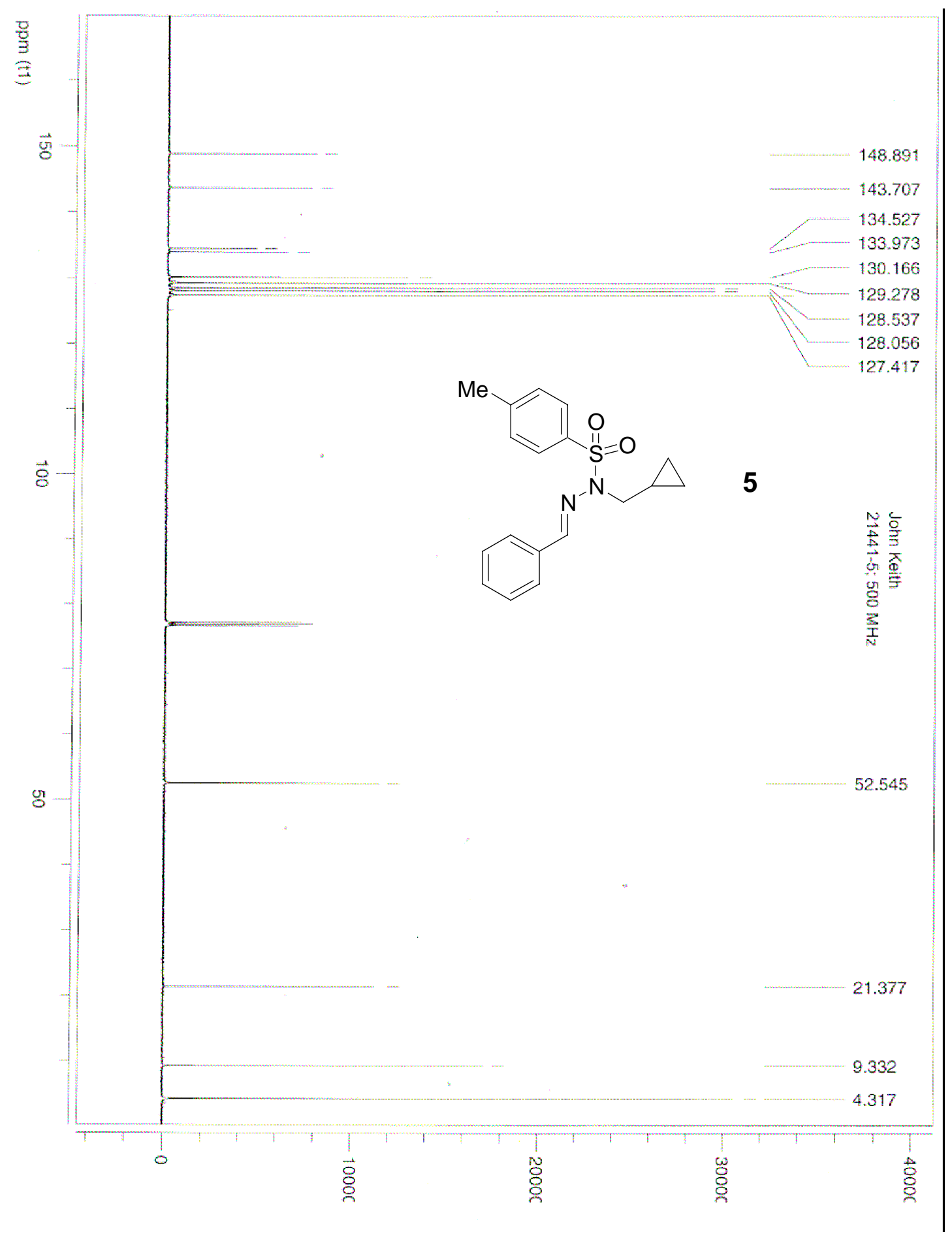




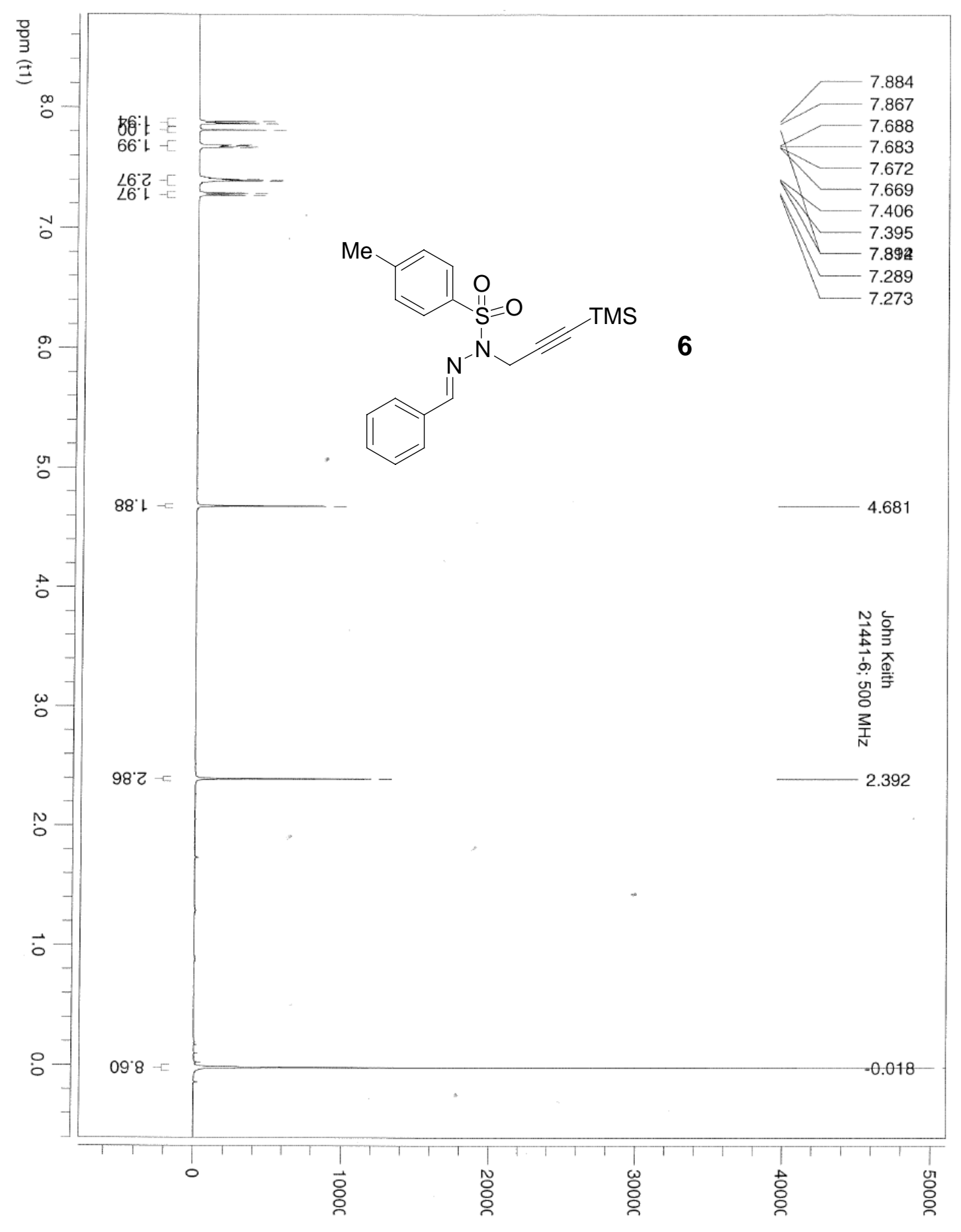




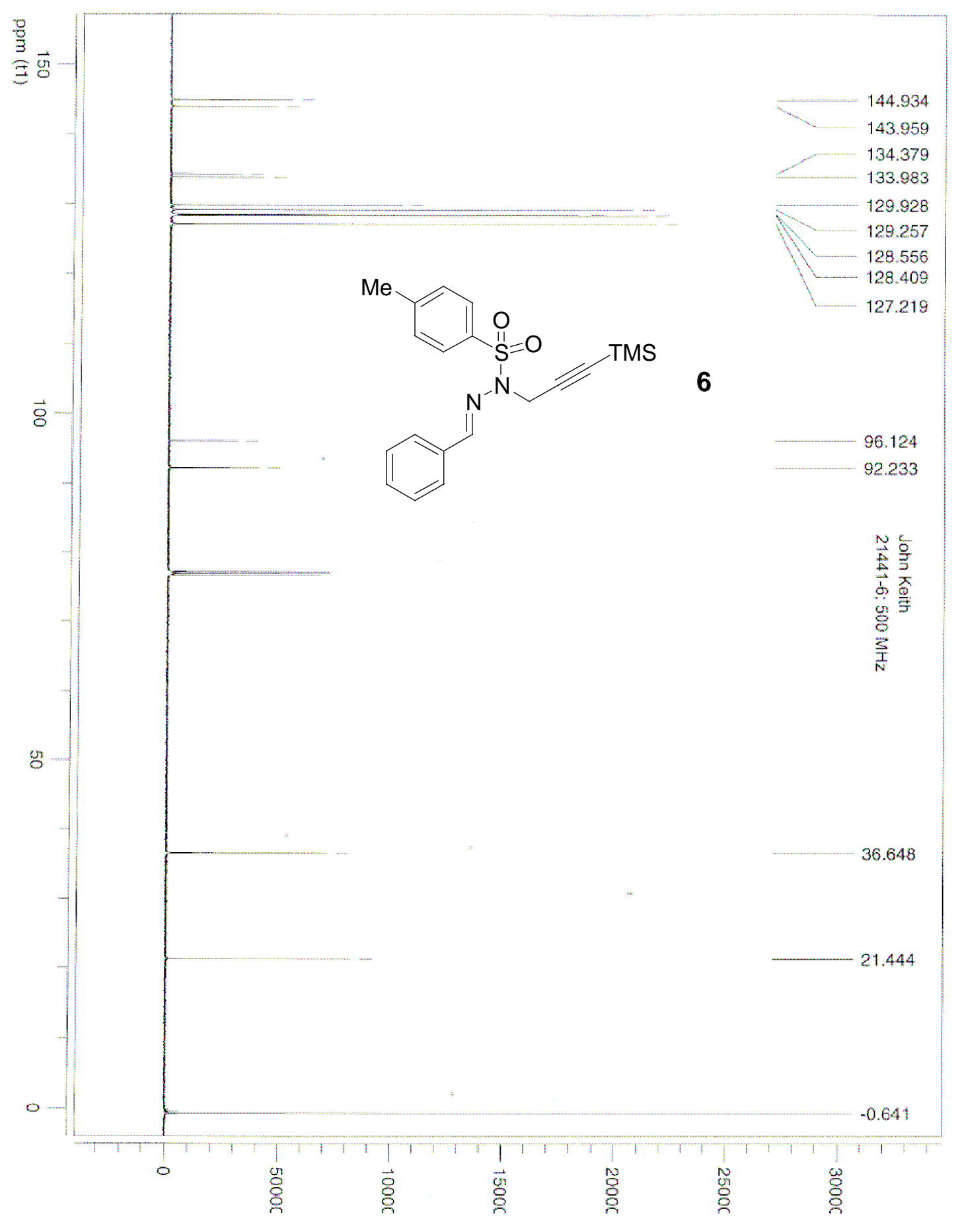




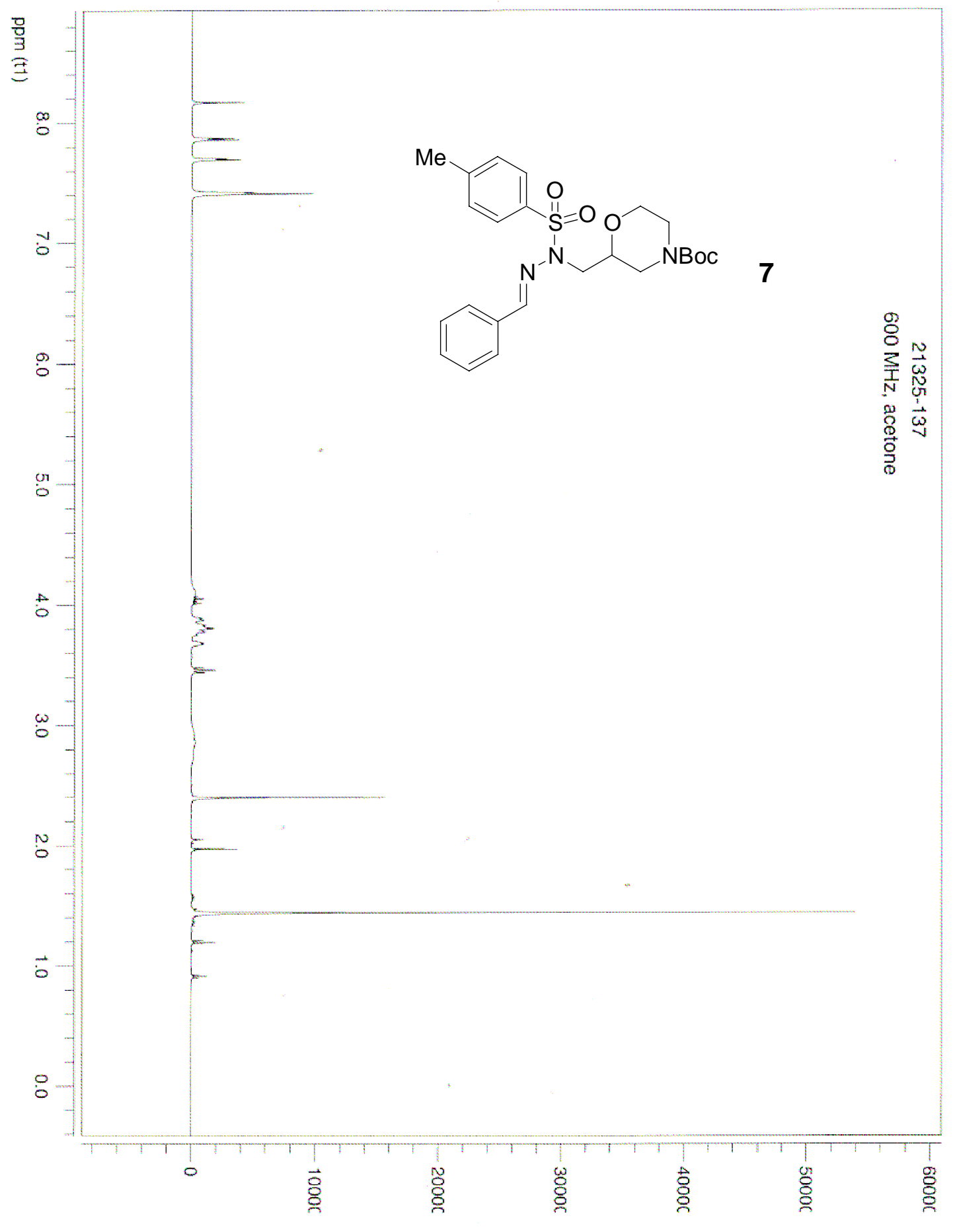




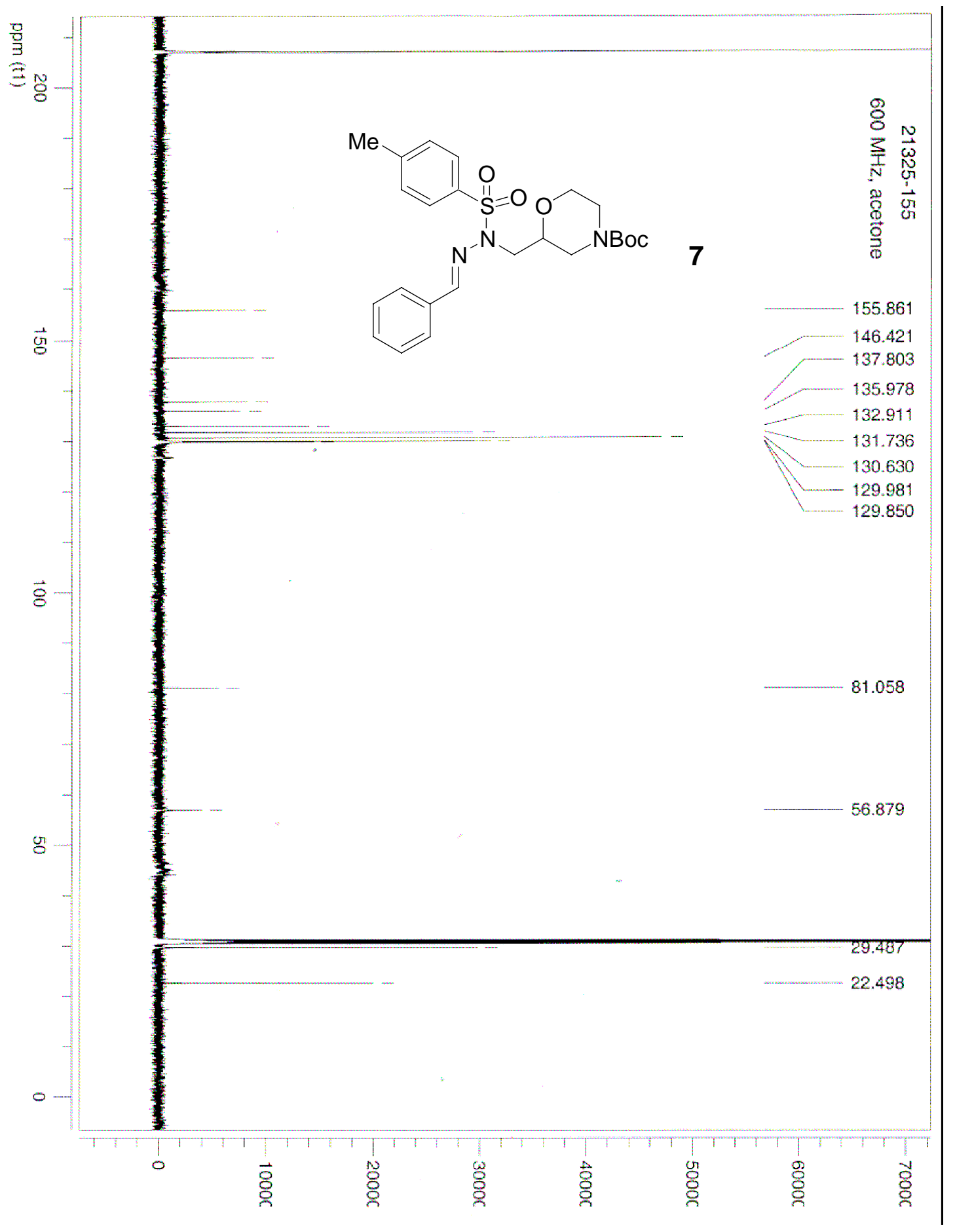




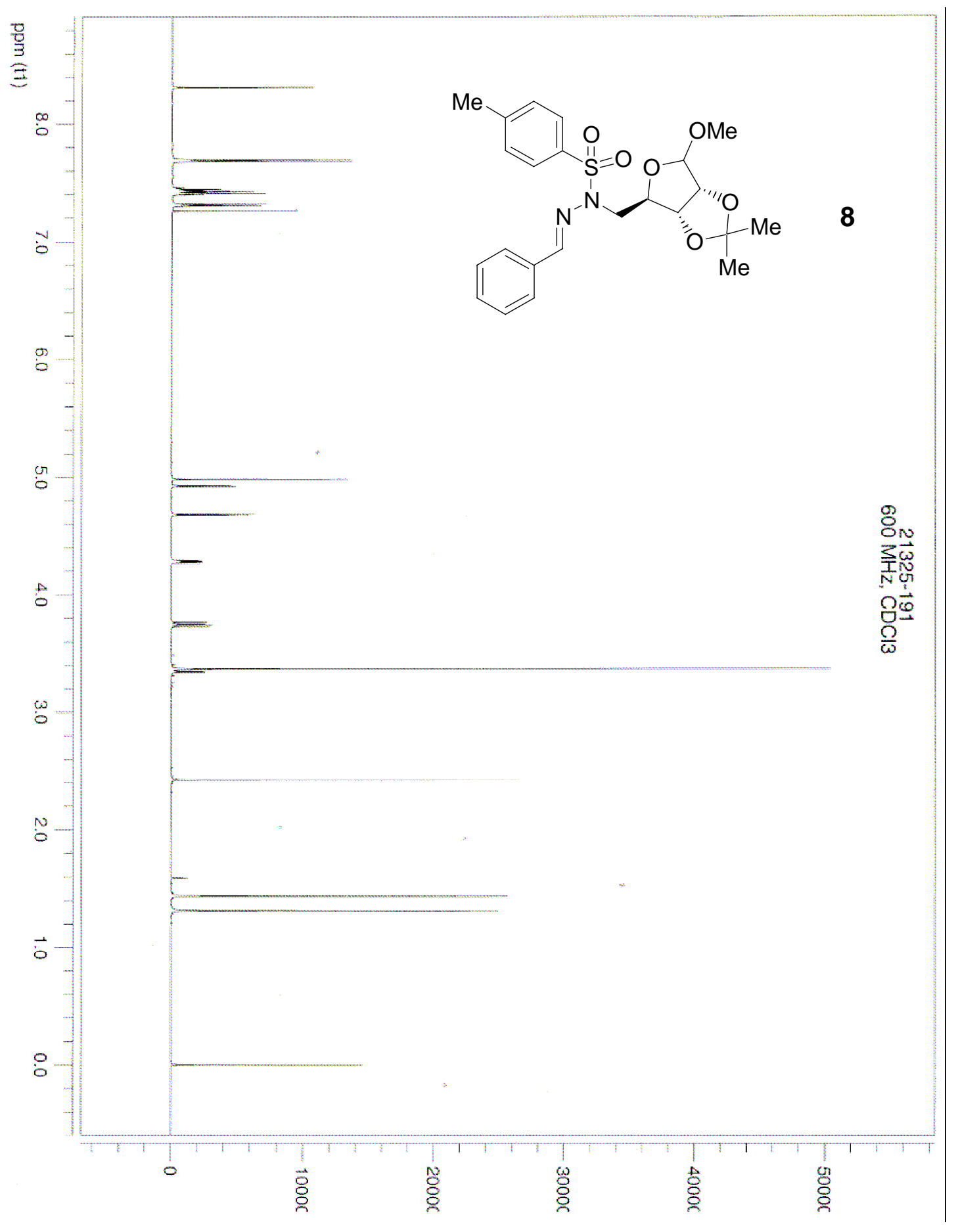




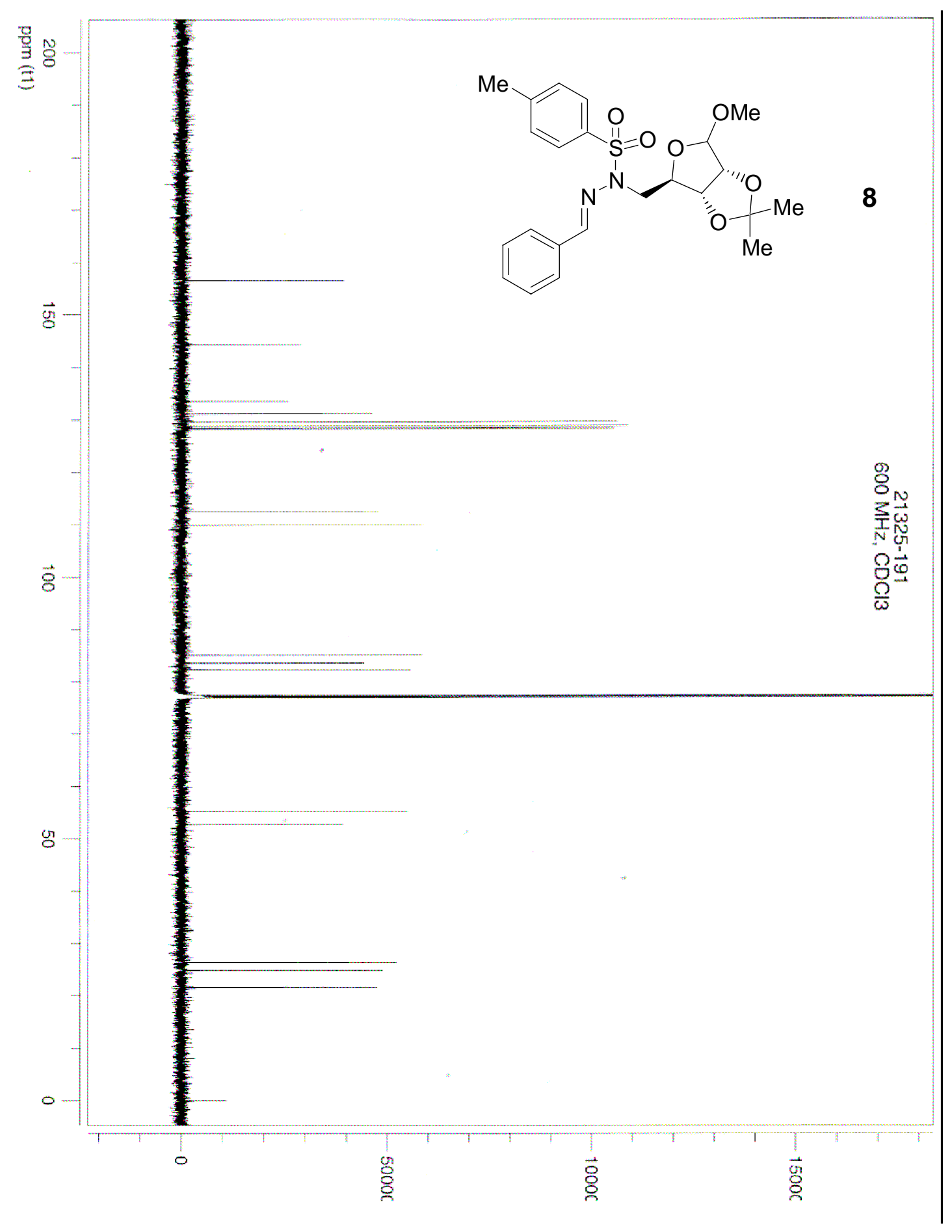




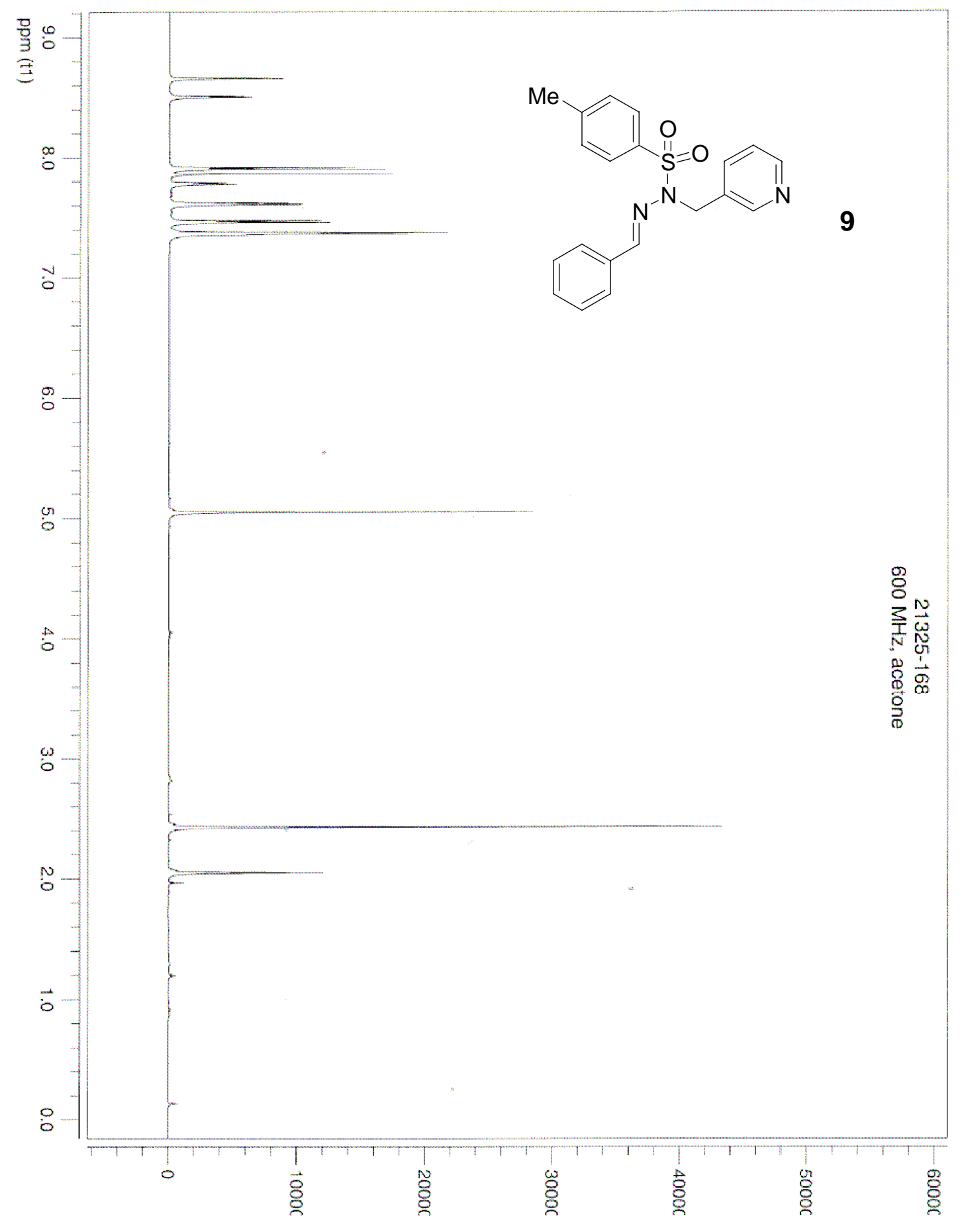




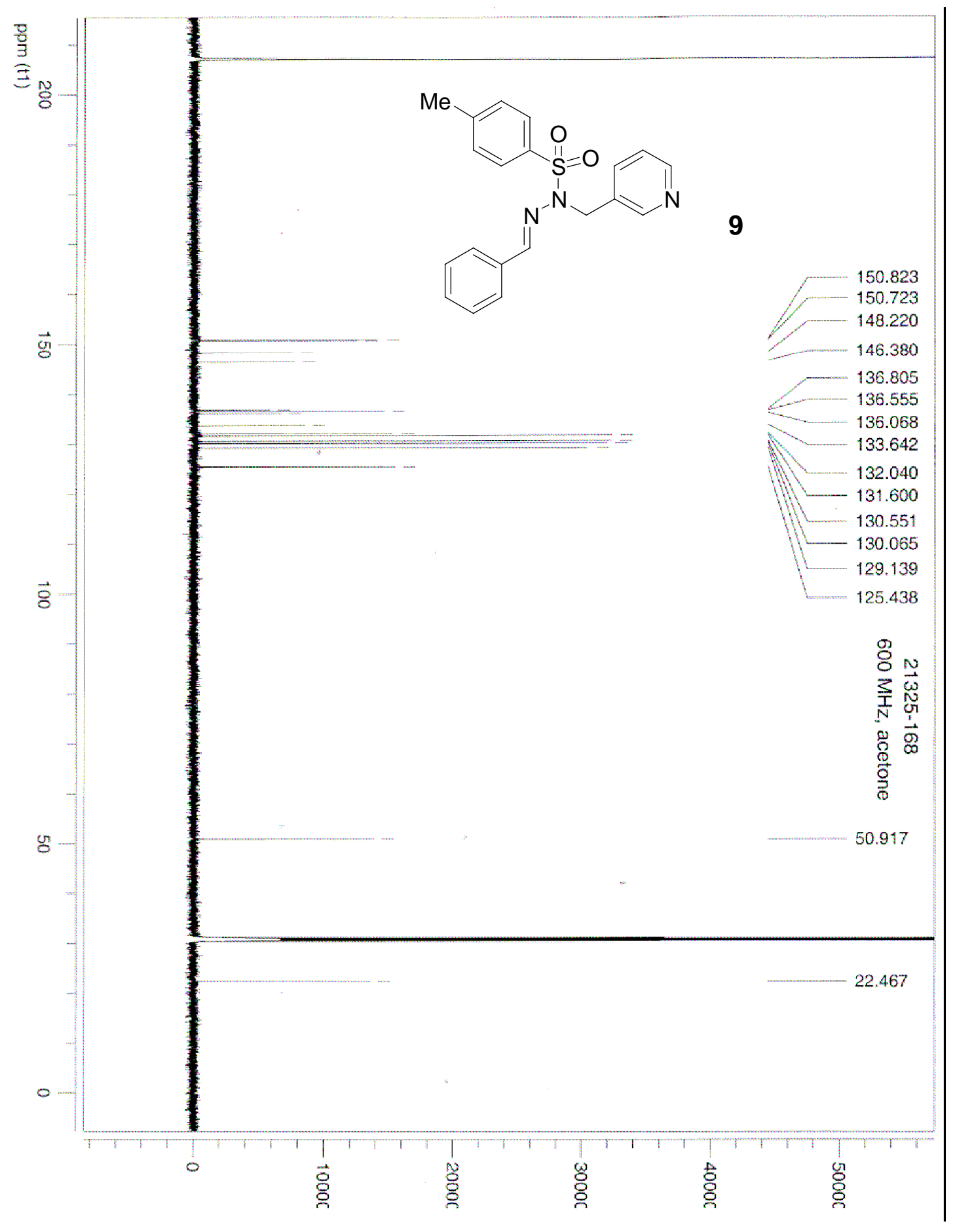




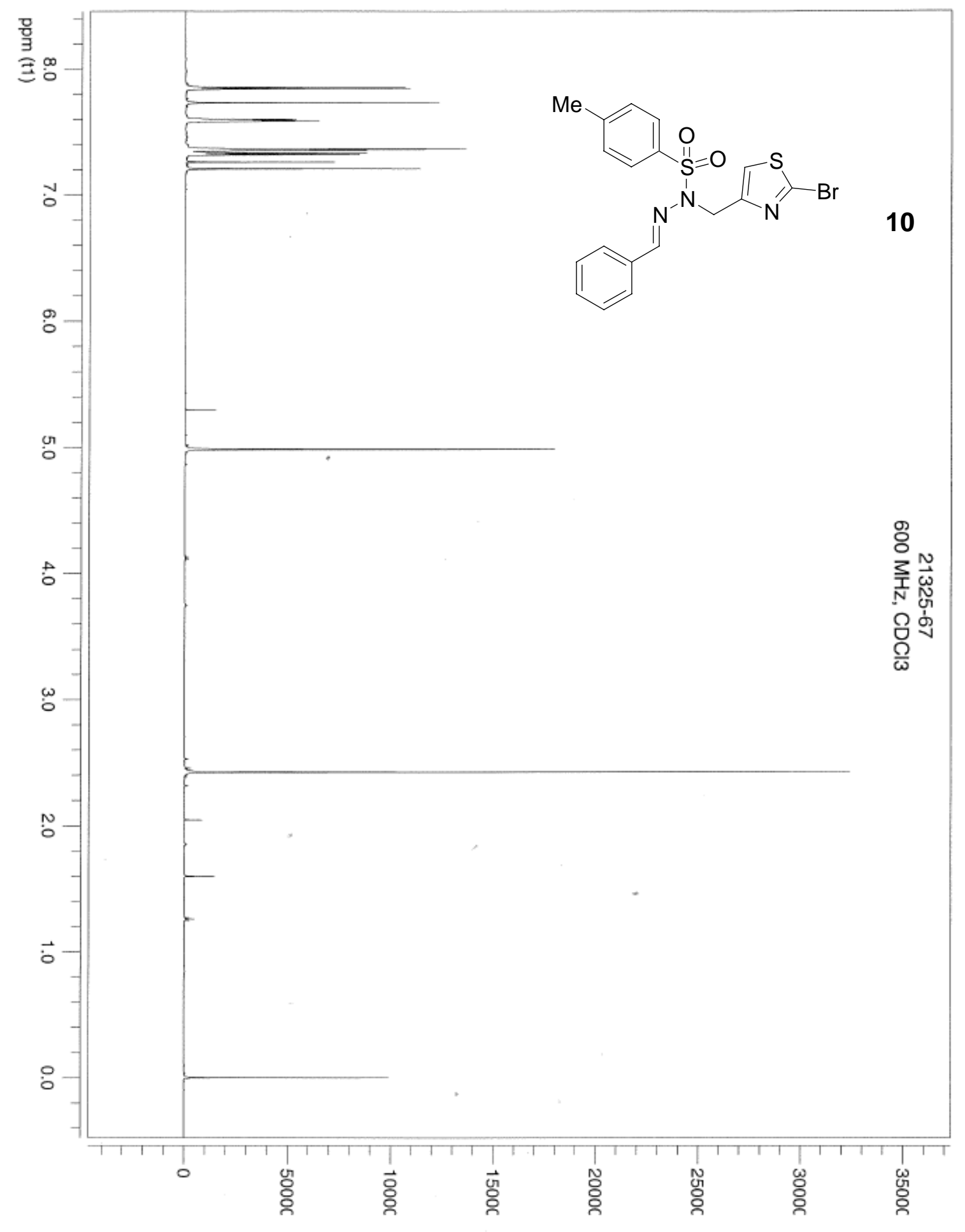




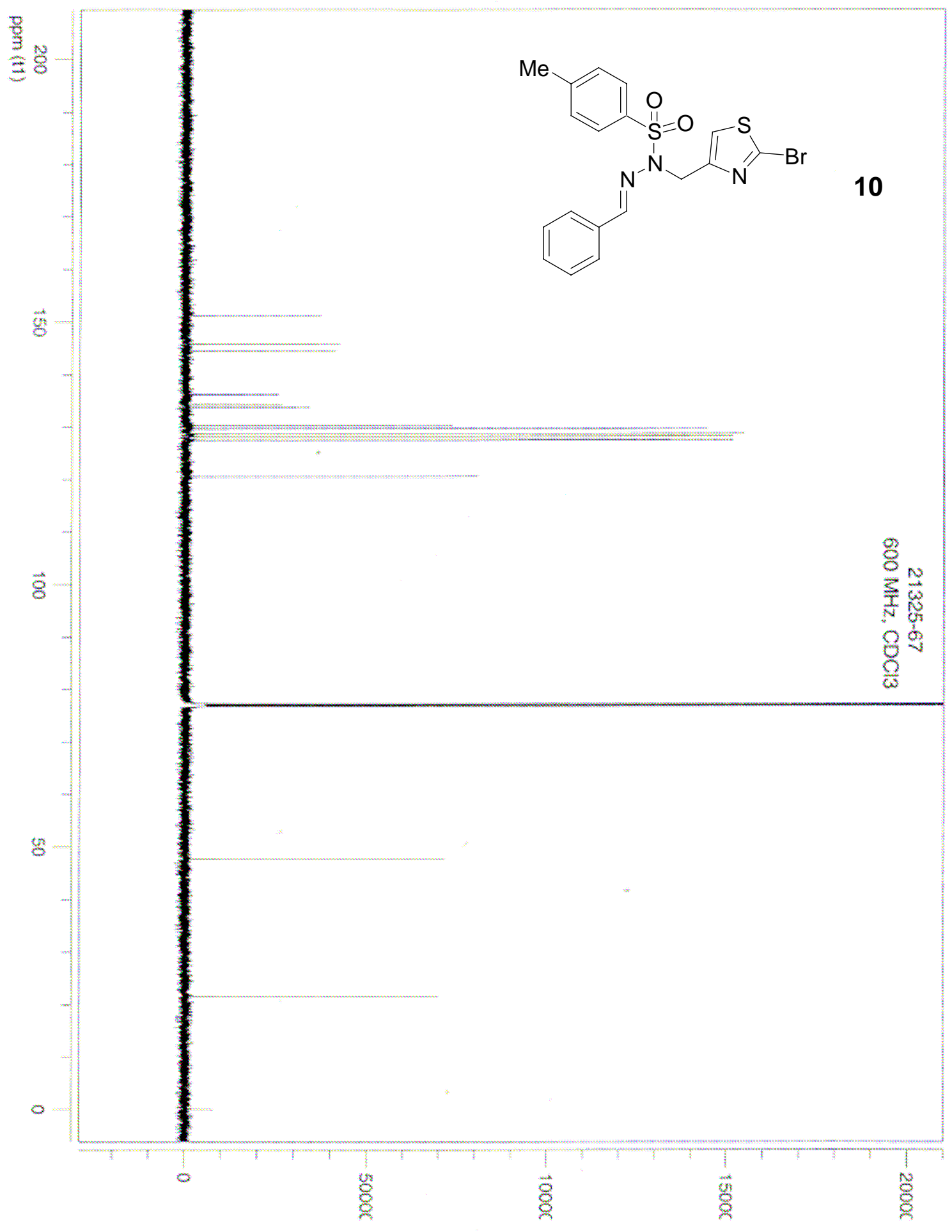




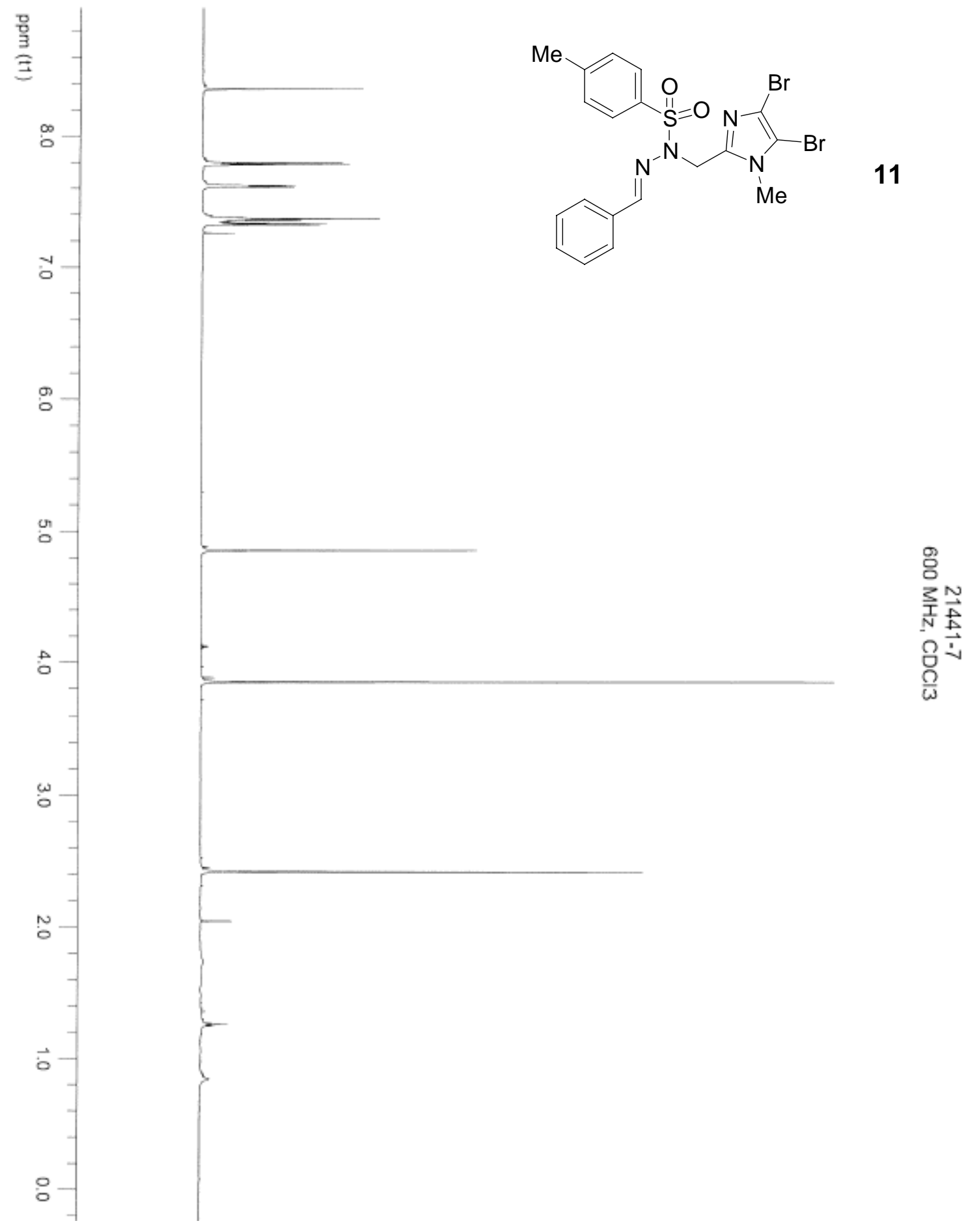




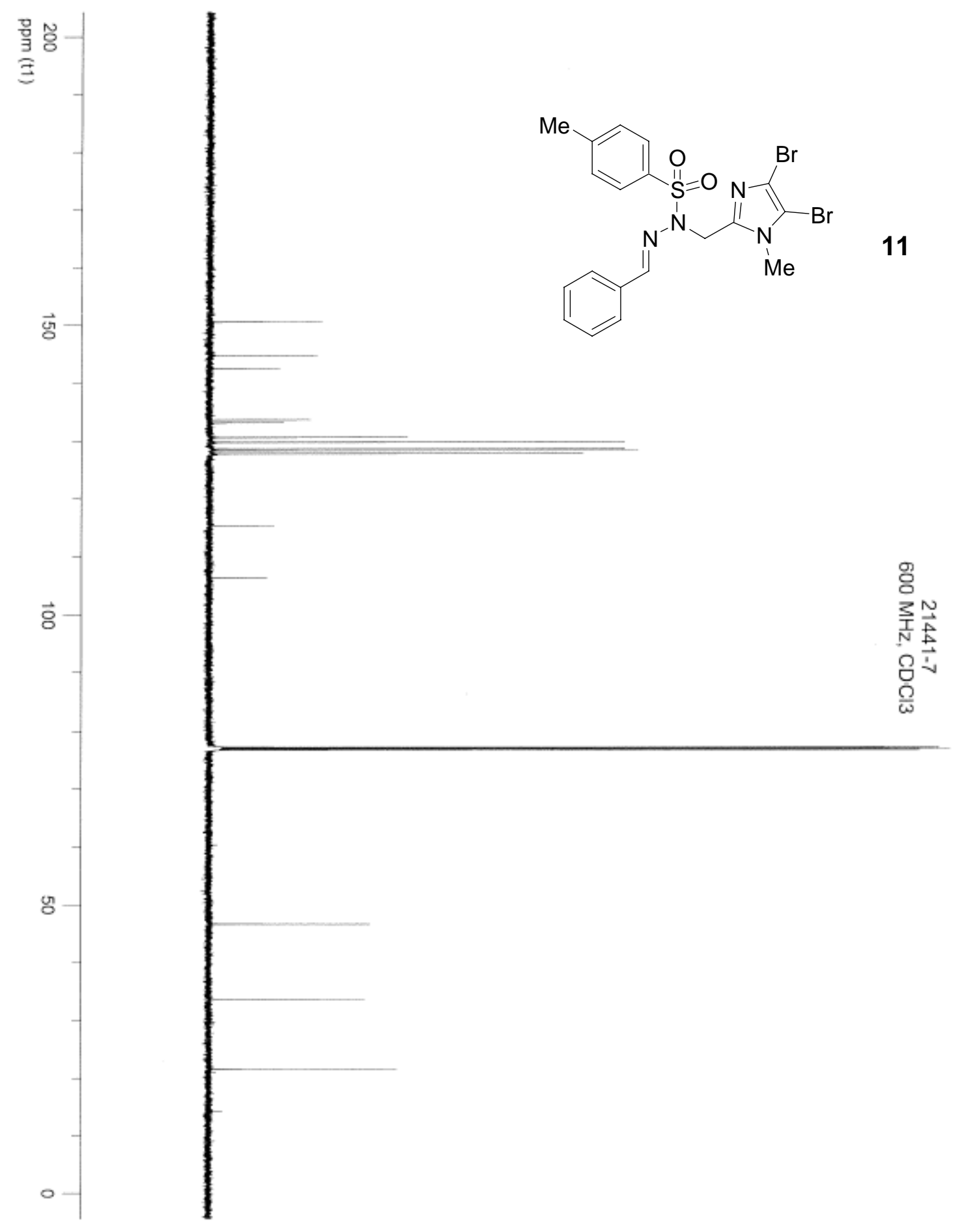




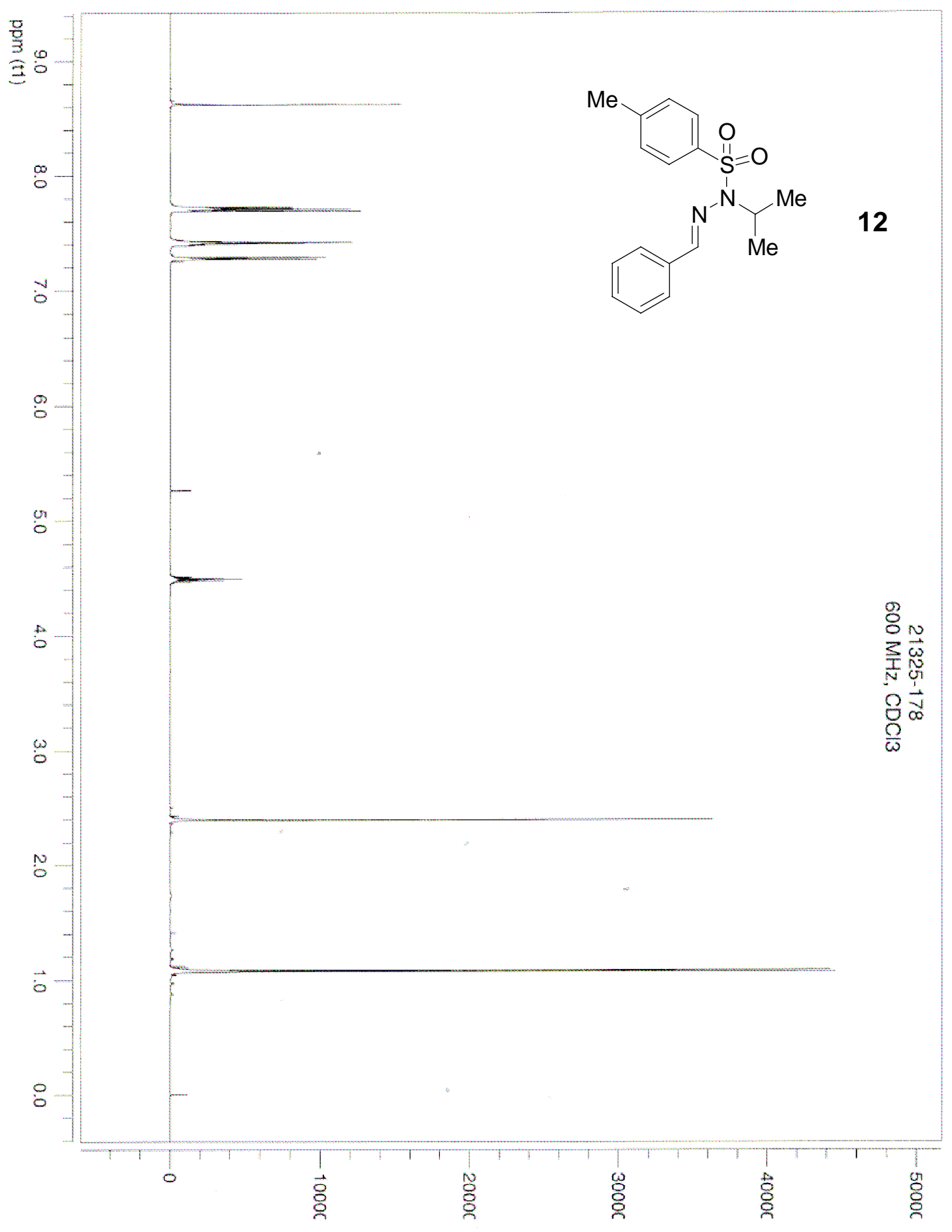




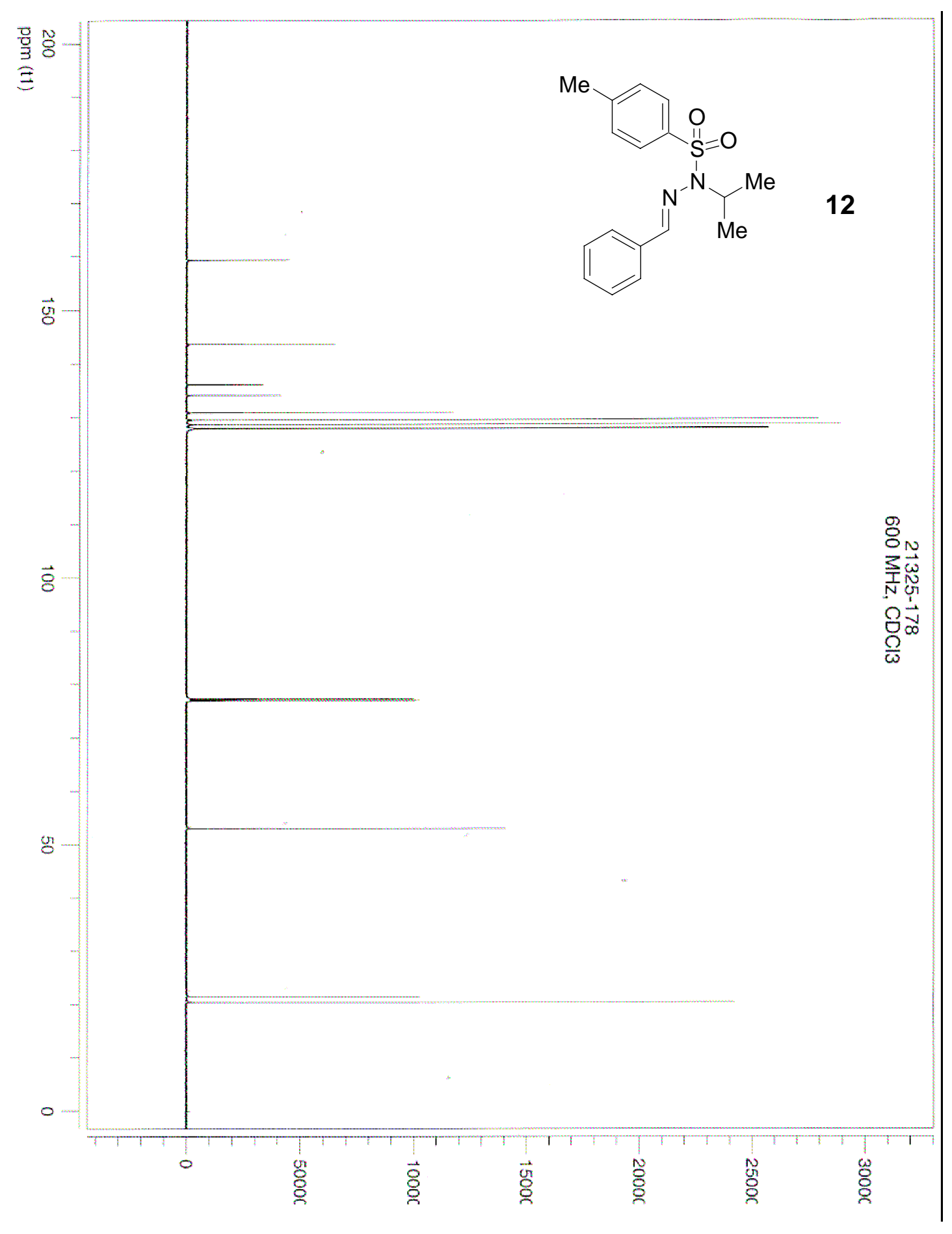




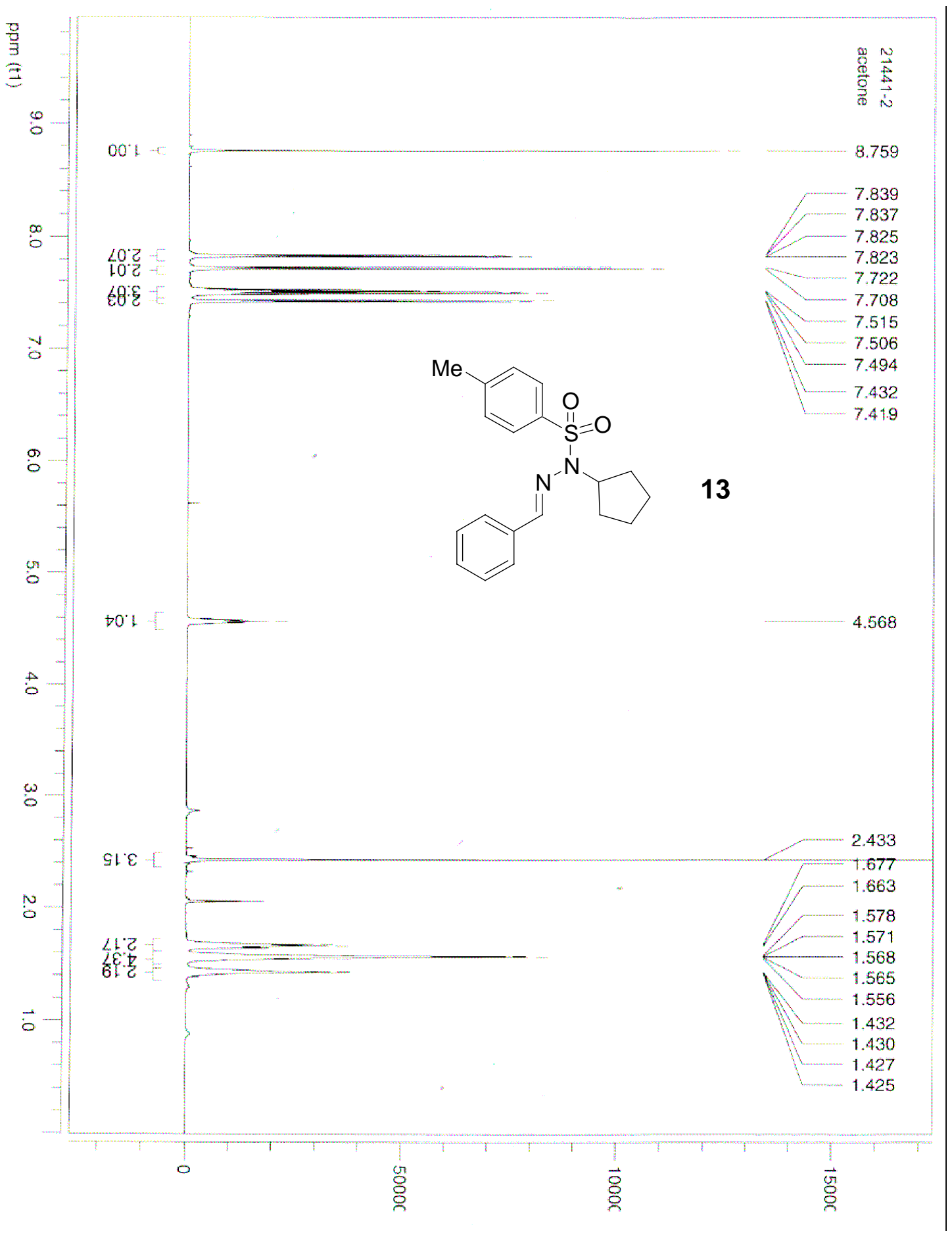




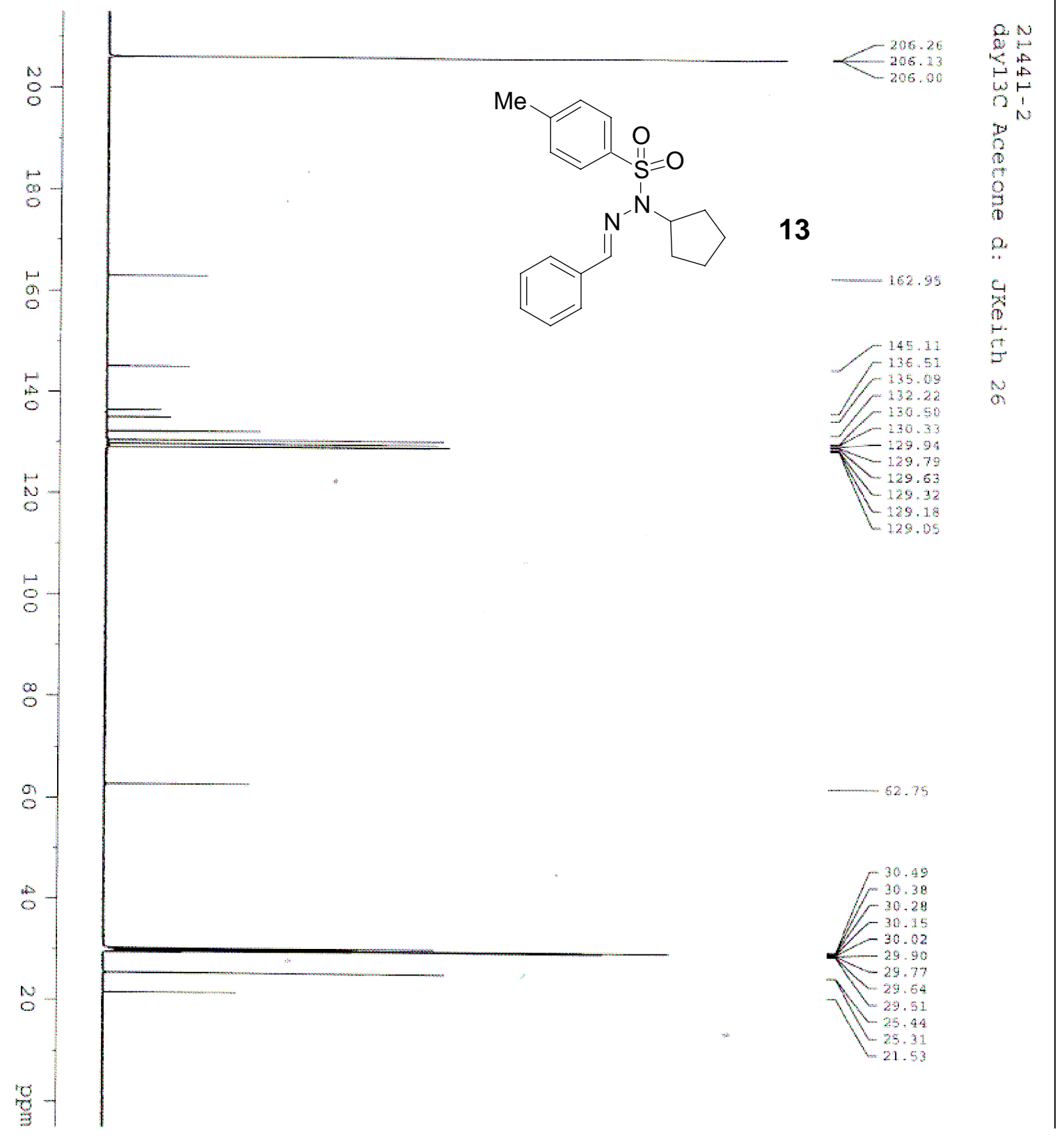




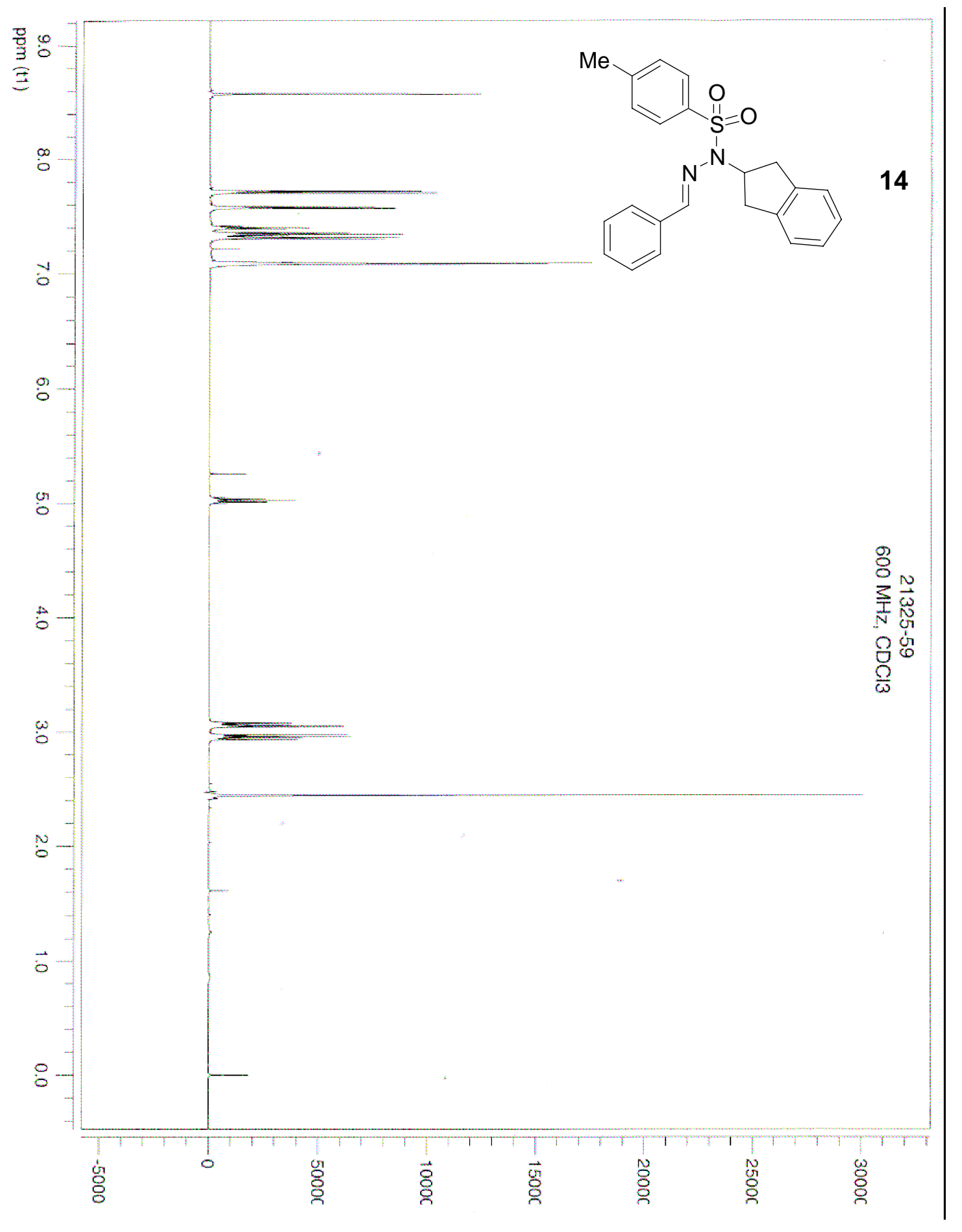




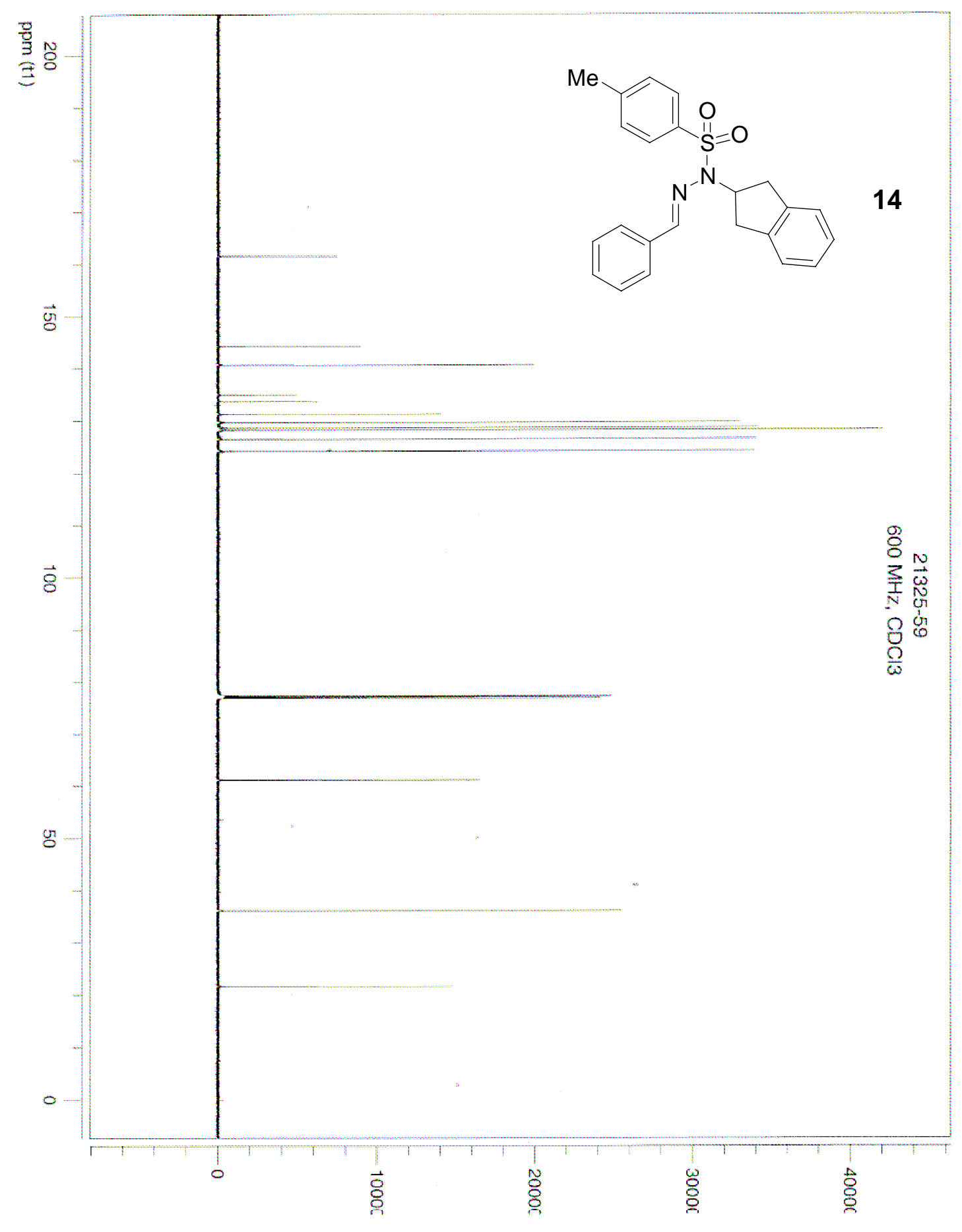




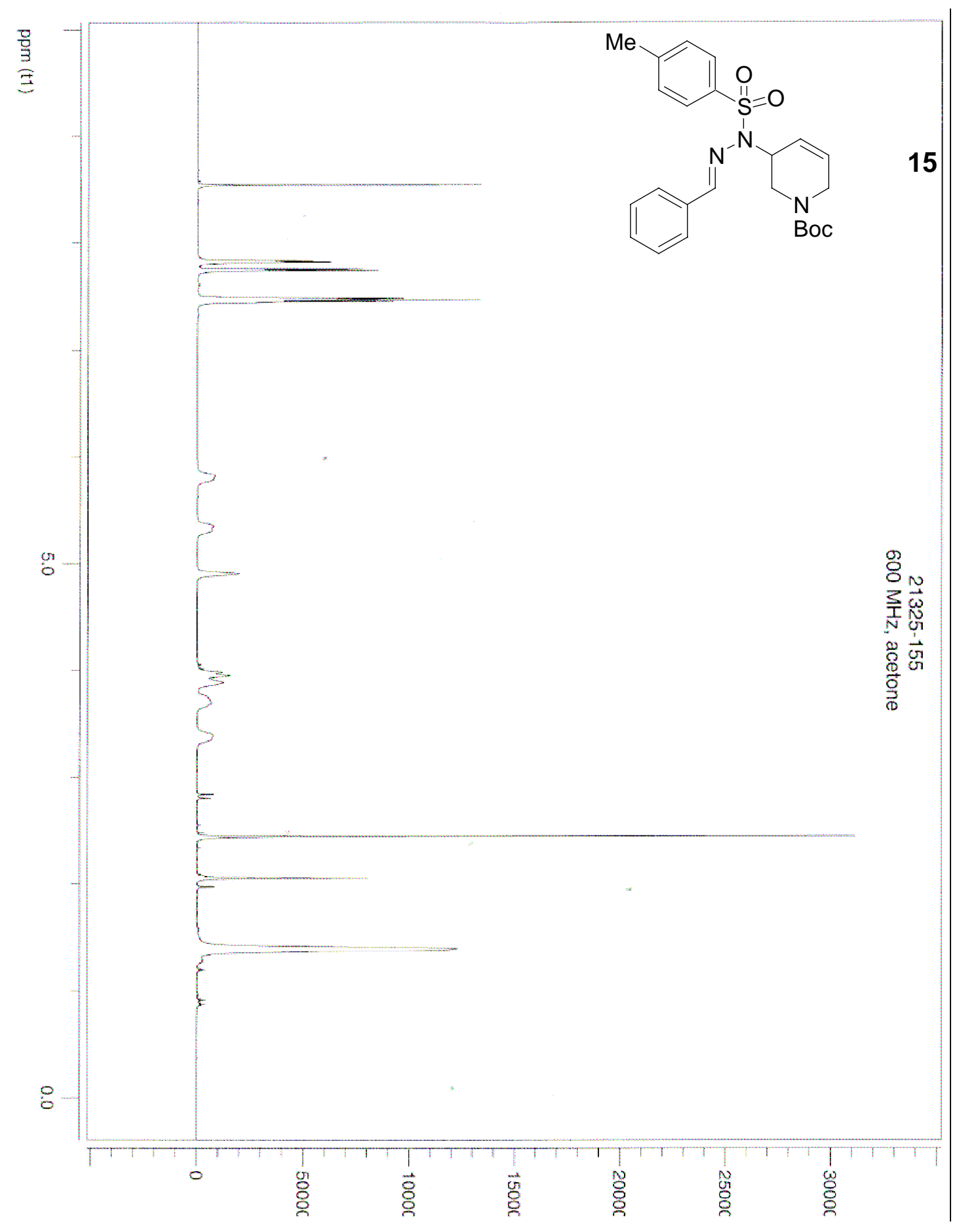




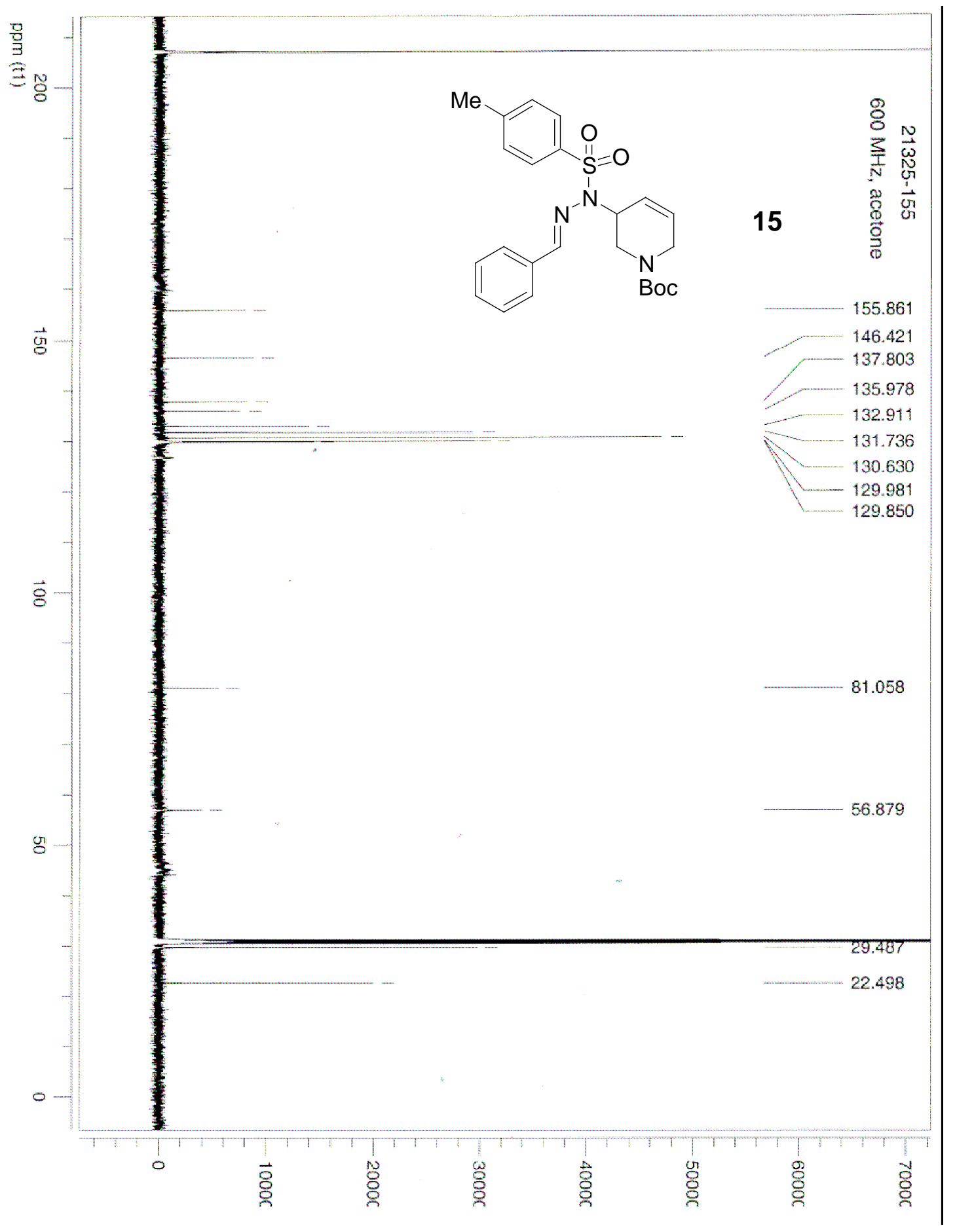




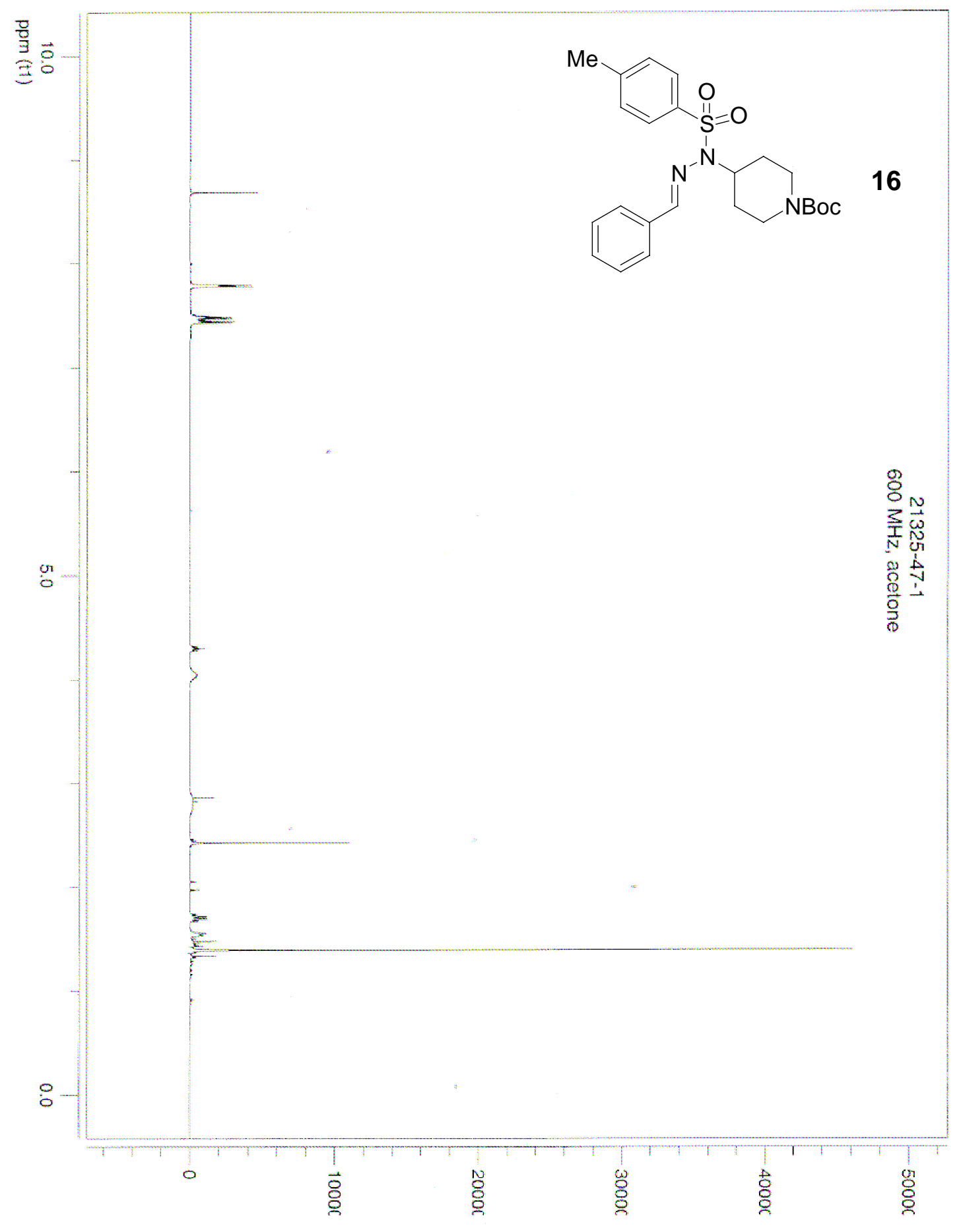




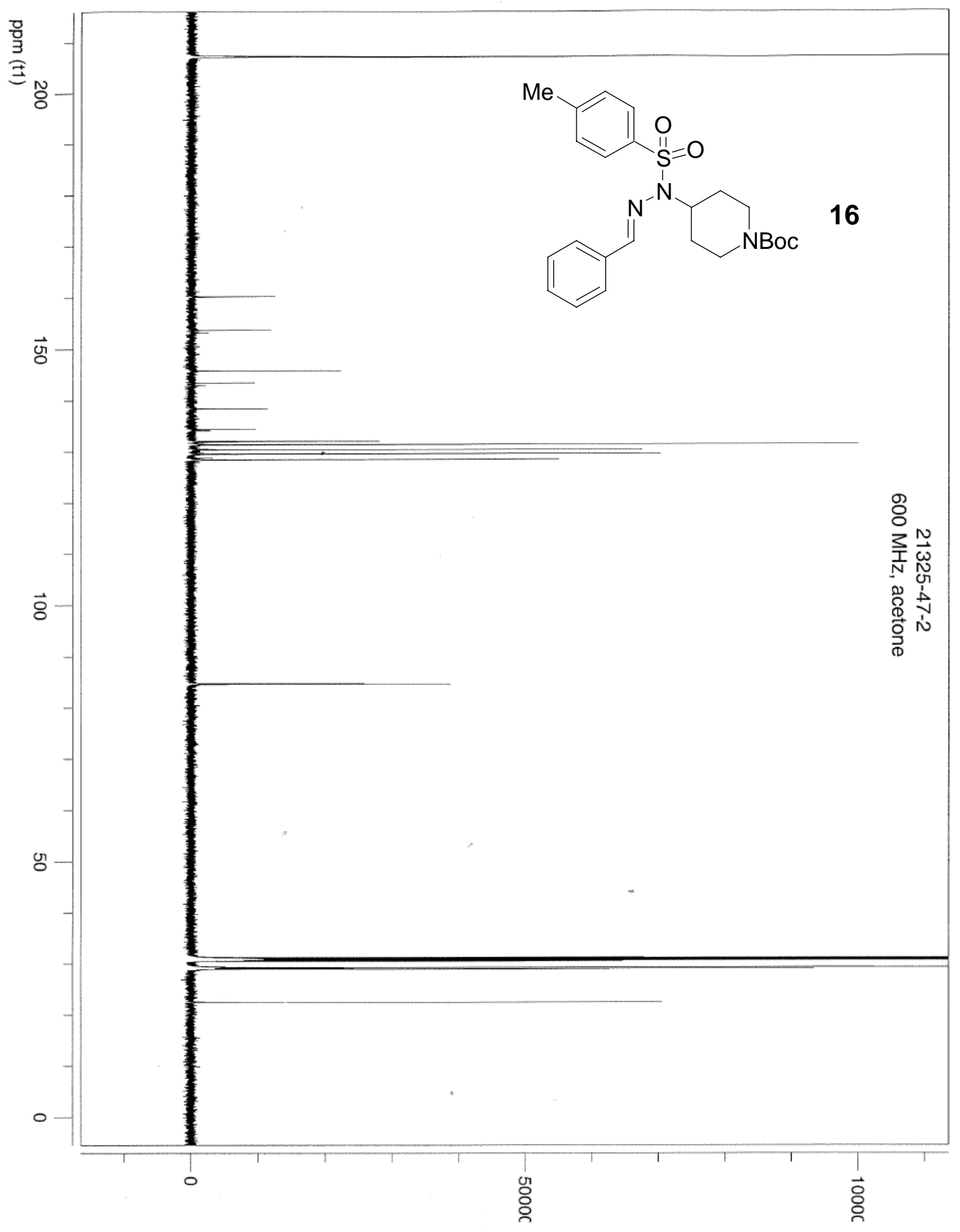




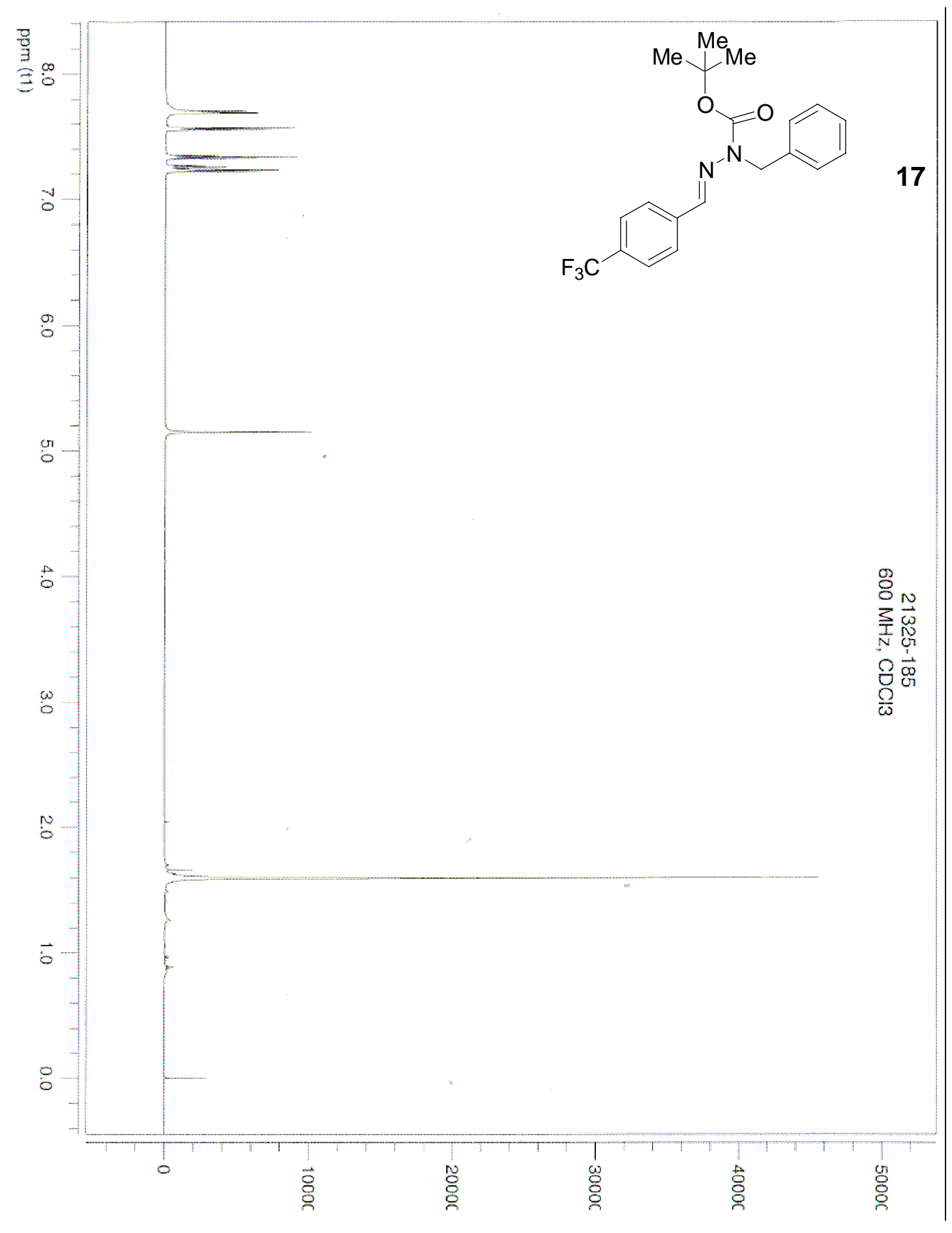




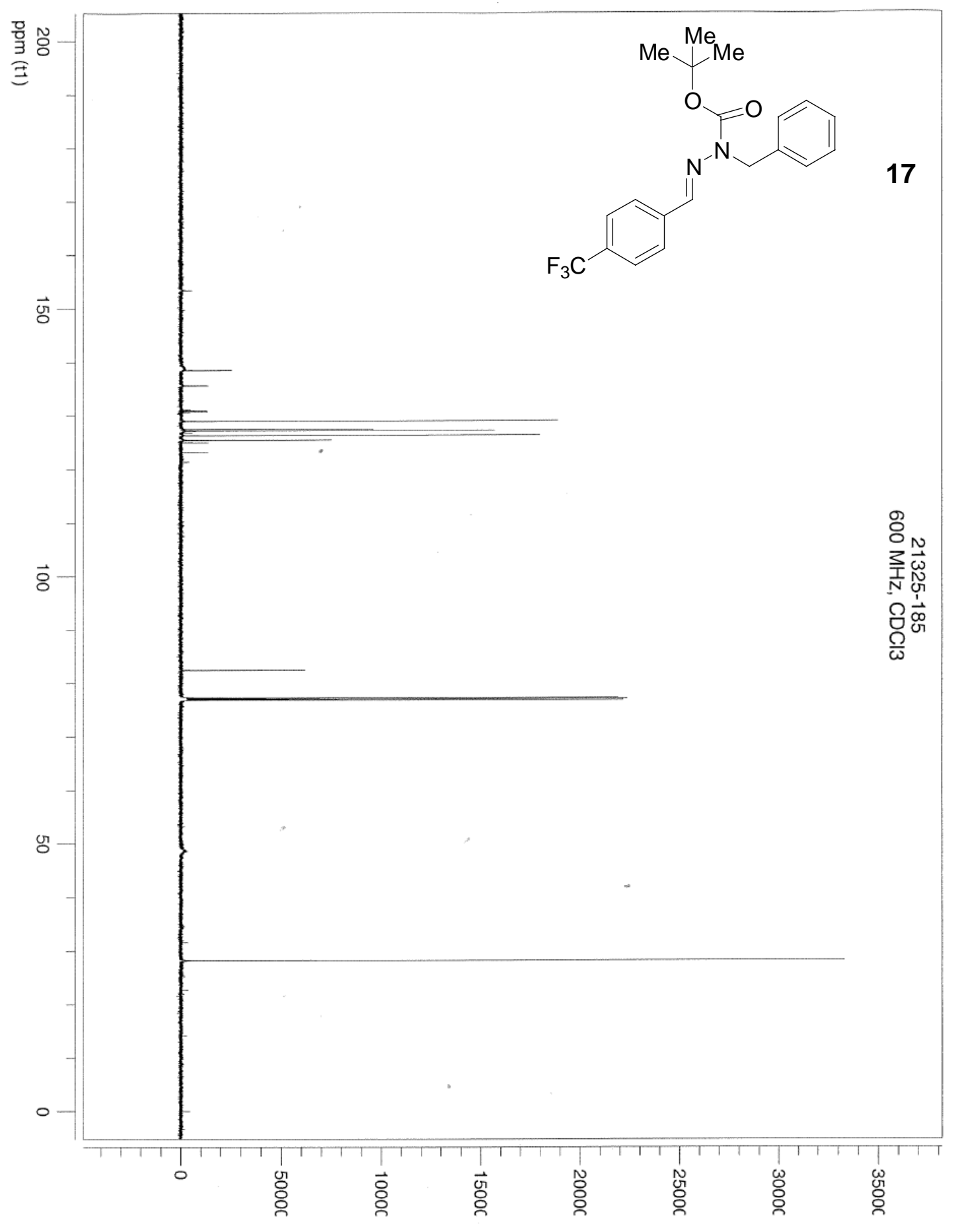




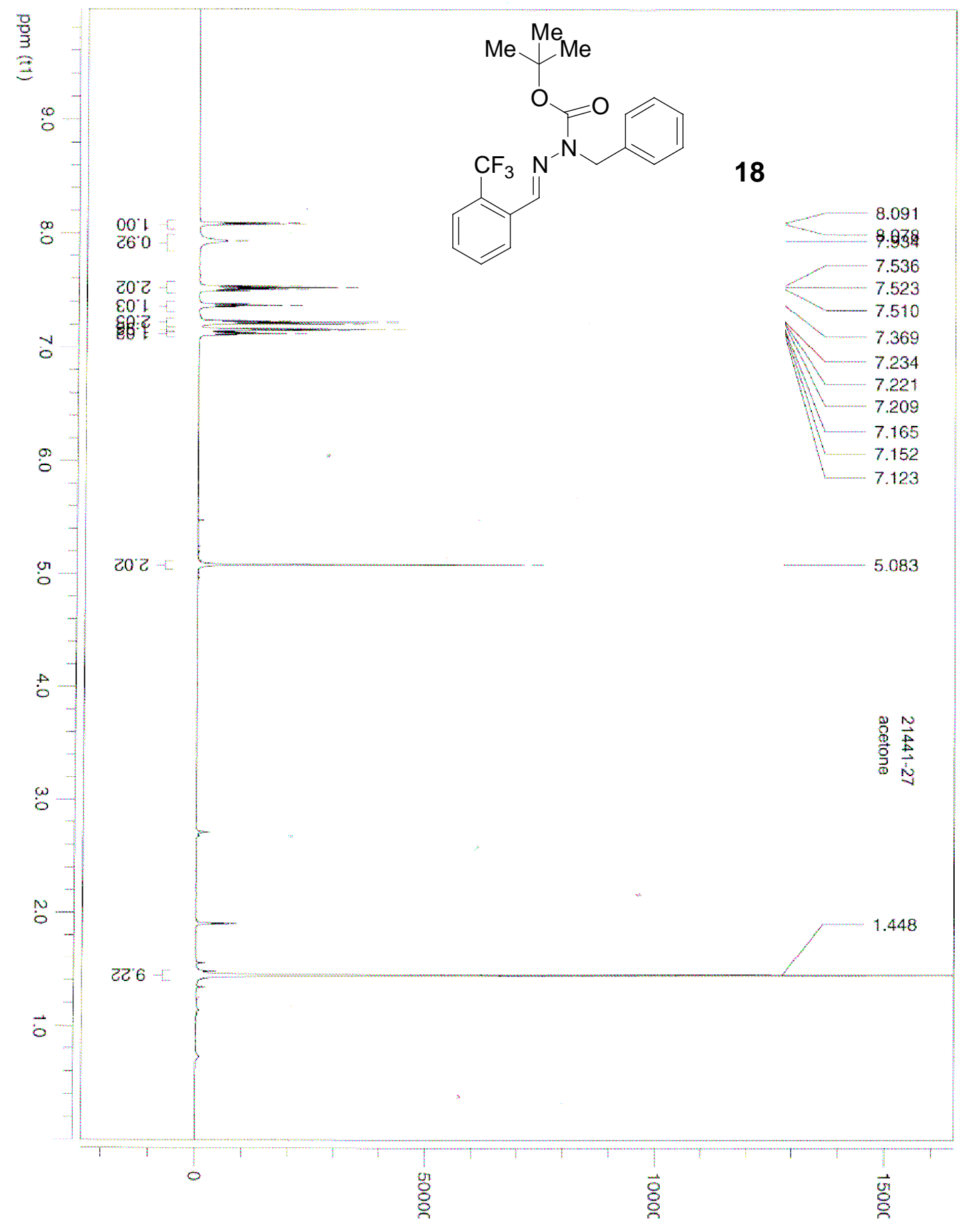




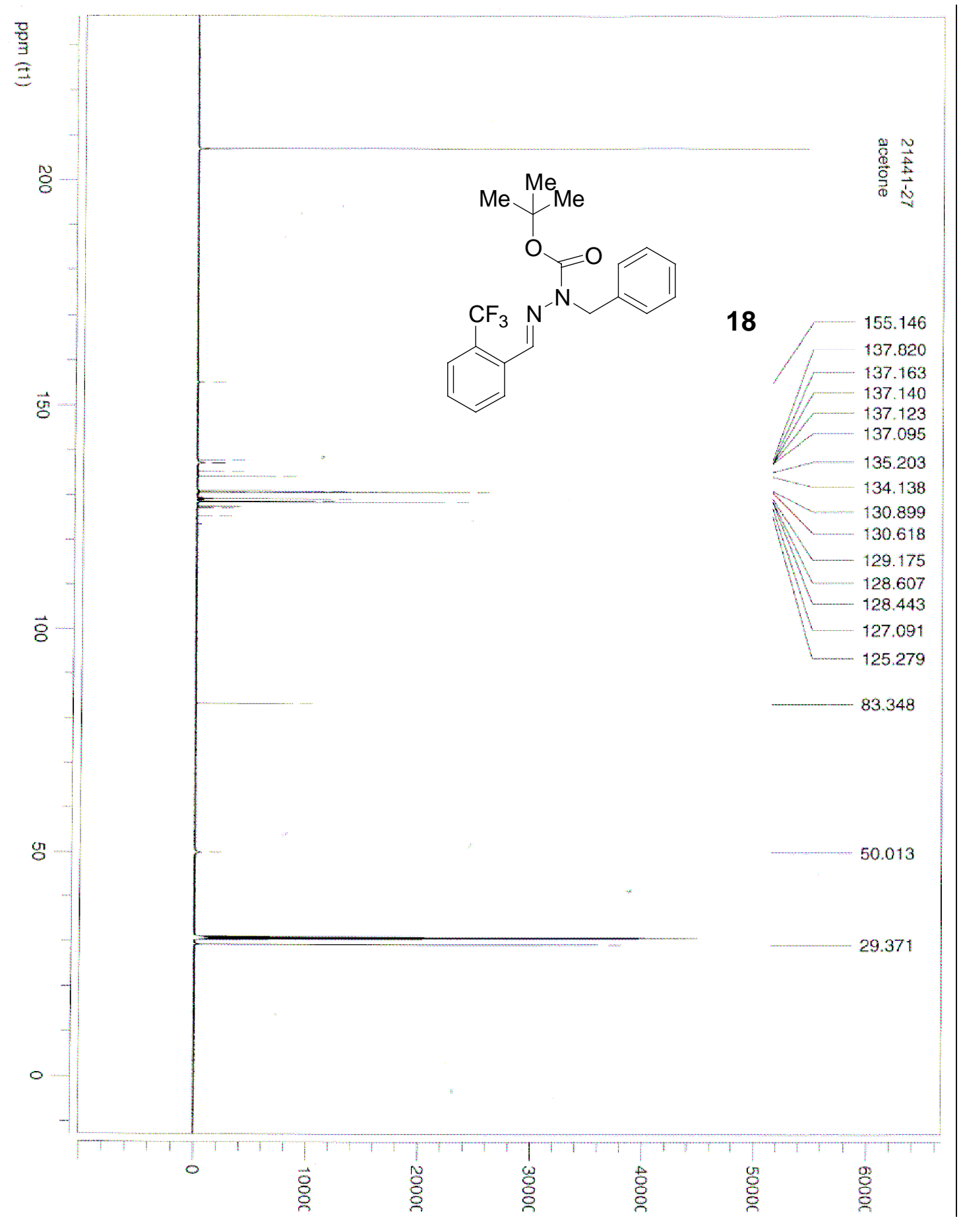




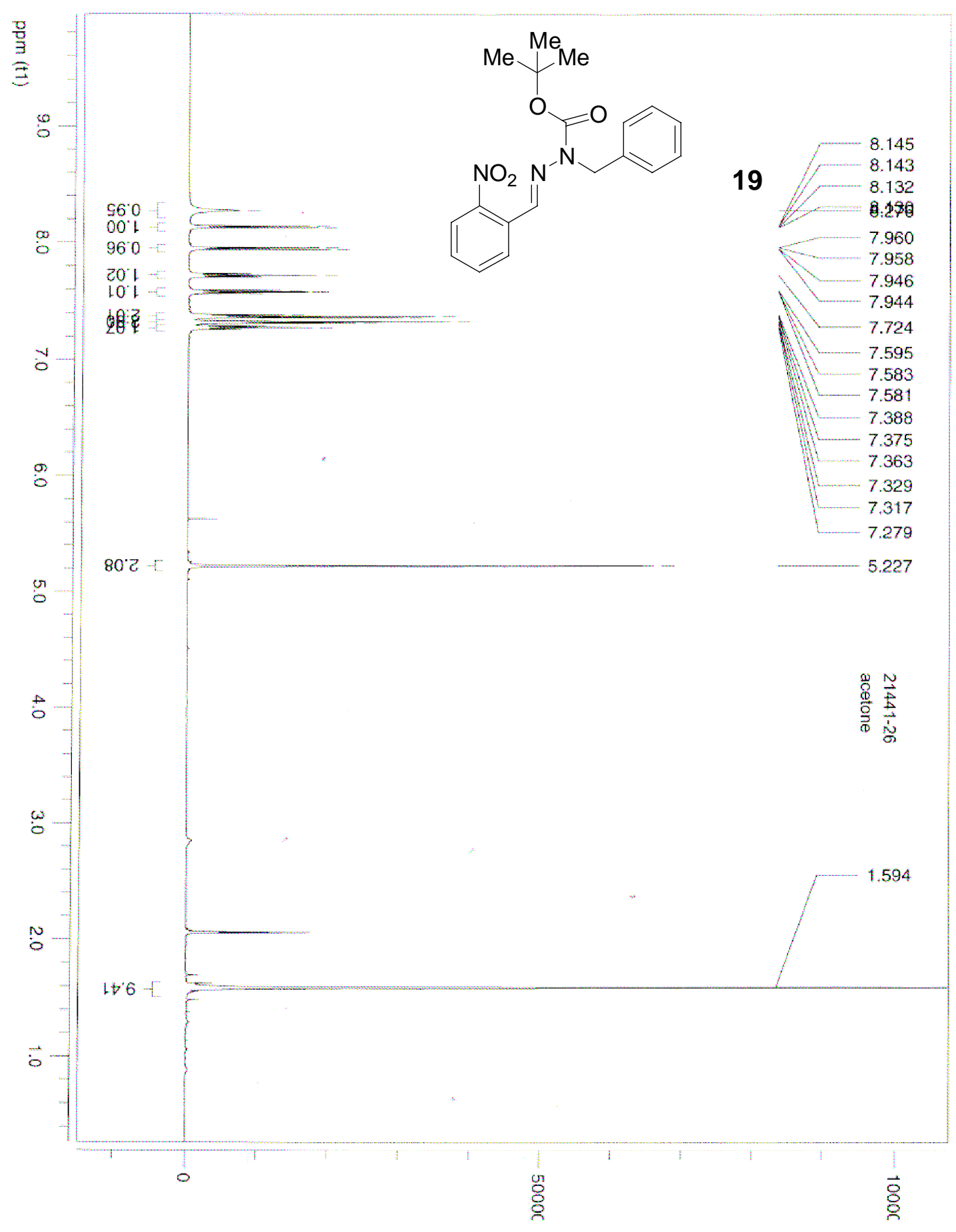




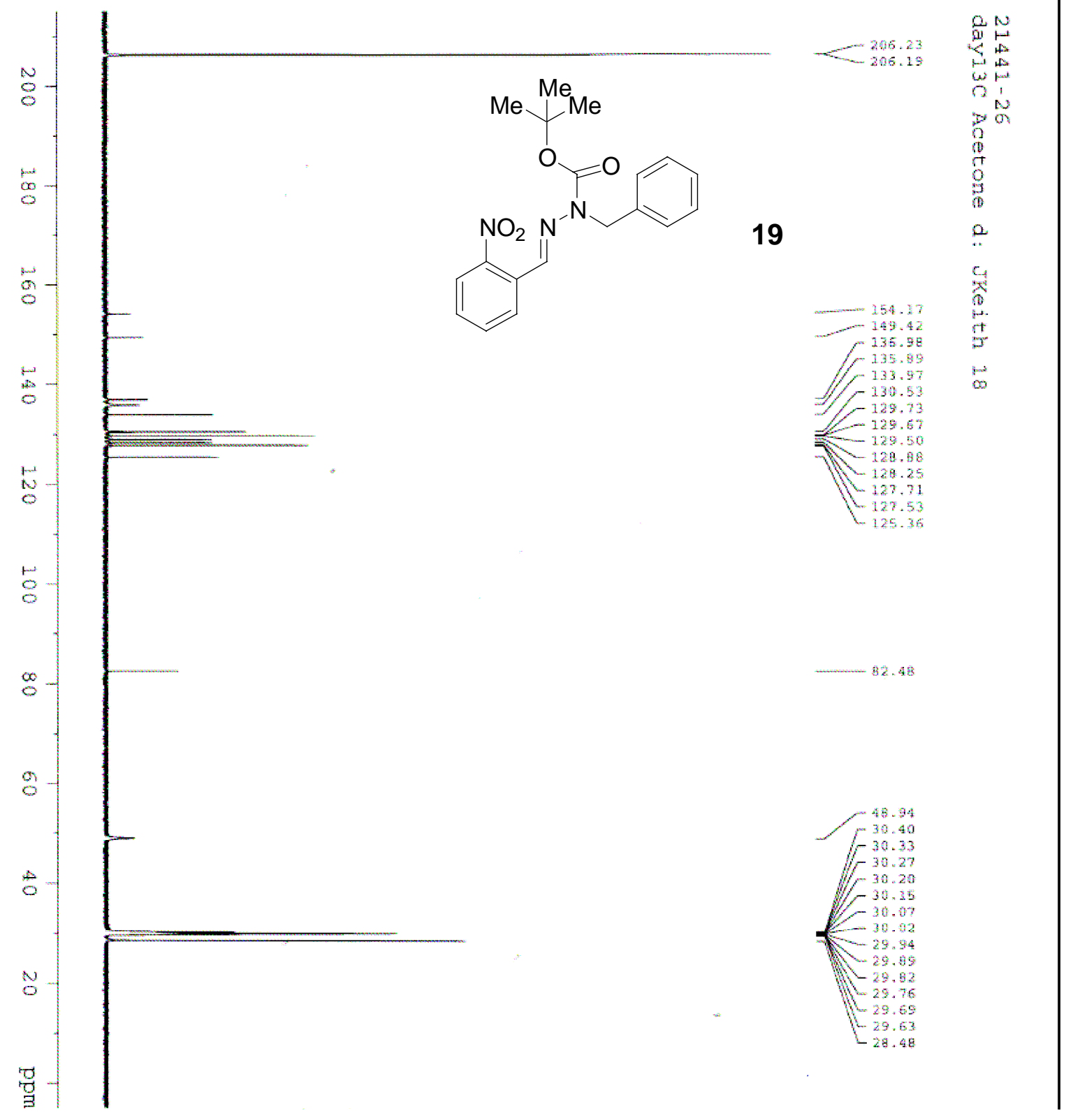




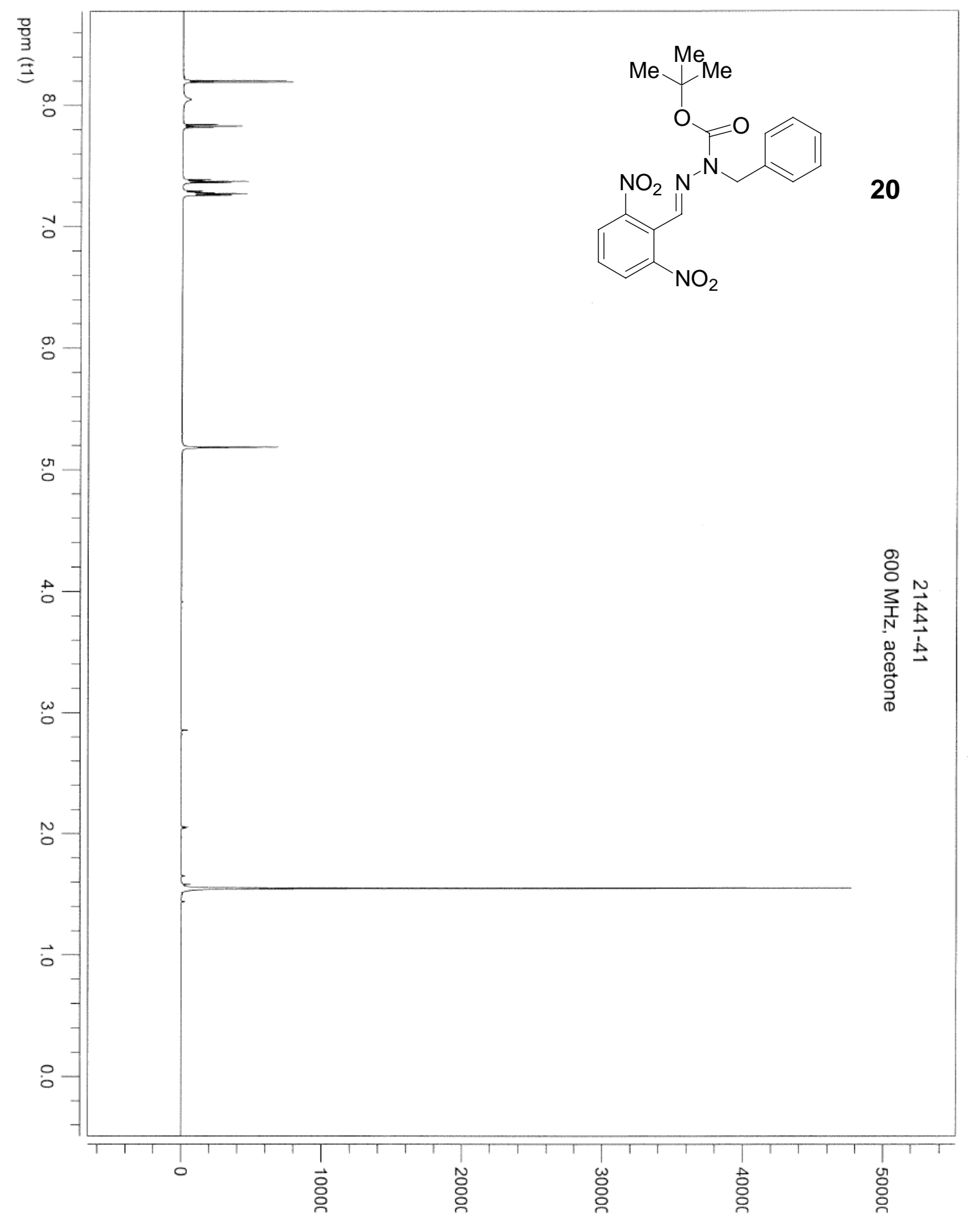




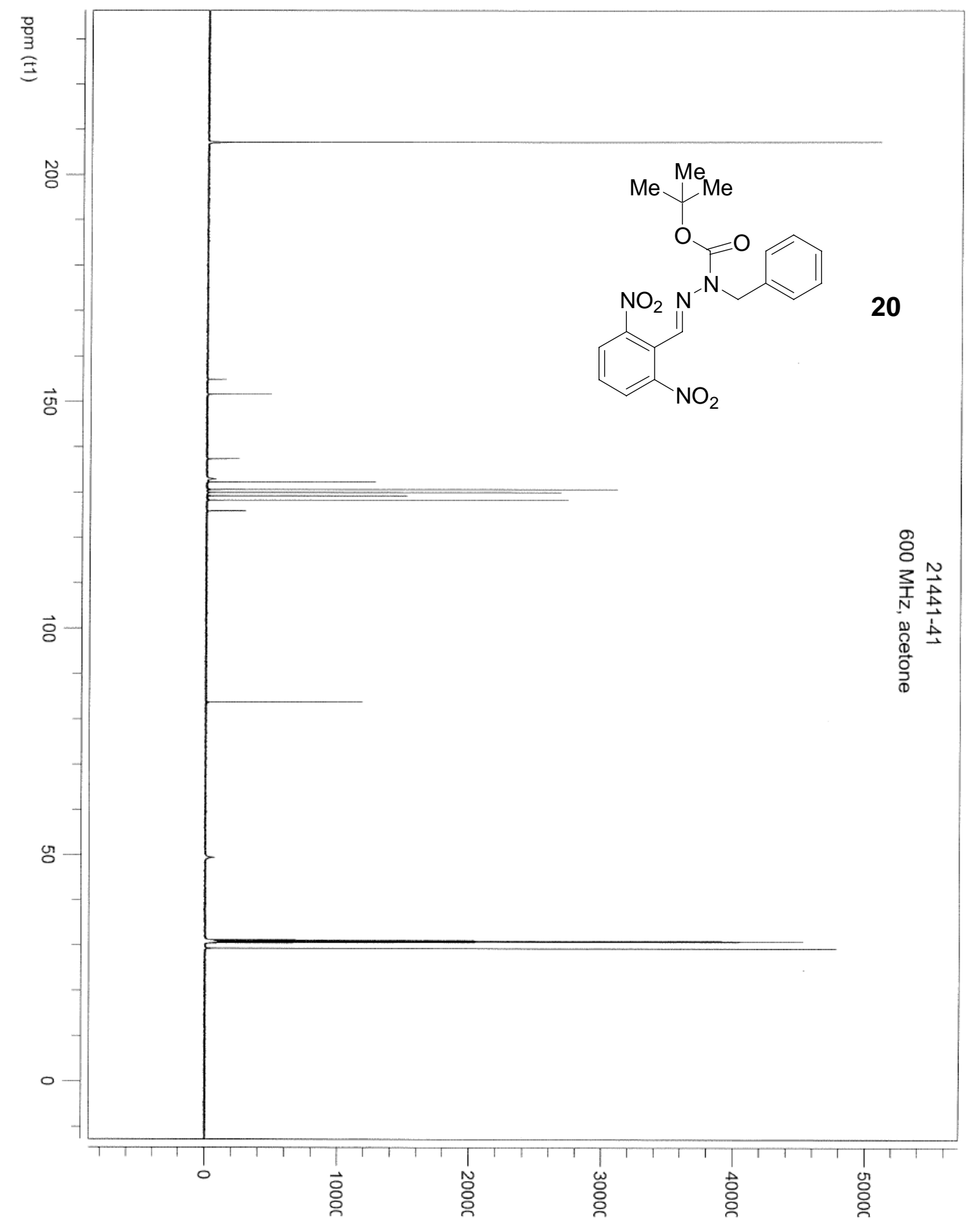

